\title{
Forward osmosis membranes and processes: A comprehensive review of research trends and future outlook
}

\author{
Wafa Suwaileh $^{\mathrm{a}}$, Nirenkumar Pathak ${ }^{\mathrm{b}}$, Hokyong Shon ${ }^{\mathrm{b} \dagger}$, Nidal Hilala,c* \\ ${ }^{a}$ Centre for Water Advanced Technologies and Environmental Research (CWATER), \\ College of Engineering, Swansea University, Swansea, SA1 8EN, UK \\ ${ }^{b}$ Centre for Technology in Water and Wastewater (CTWW), School of Civil and \\ Environmental Engineering, University of Technology Sydney (UTS), Australia. \\ ${ }^{c}$ NYUAD Water Research Center, New York University Abdu Dhabi, Abu Dhabi, United \\ Arab Emirates \\ * Corresponding author: n.hilal@swansea.ac.uk
}

\begin{abstract}
Recently, Forward Osmosis (FO) desalination process has been widely investigated as a potential technology that could minimize the drawbacks of traditional desalination processes. To review the past, current, and future research scope of the FO desalination process, a statistical analysis that gives insights on the FO topics of interest is needed to assist researchers in the development of the FO technology. The main objective of this work is to conduct a survey highlighting the general and specific research trends in FO technology topics. The level of research interest is quantified based on the number of publications in each area collected from Science Direct and Scopus databases from 1999 to 2020. This survey indicated an increasing number of publications on the FO processes and membranes technology. The topics of interest are fouling phenomenon, draw solutions, membrane fabrication and modification. Some potential research areas highlighted in this review to help researchers to further advance the FO technology. This review reveals that recycling the draw solution and energy consumption are the most important research areas that have shown growth in the number of publications over the last eight years. An increase of publications was also found in the treatment of the organic matter over the last decade. To further promote FO process in industry, developing FO membranes, optimizing the energy consumption, and establishing an effective
\end{abstract}


recovery system are the most essential topics. Thus, the interest in this process is expected to be continued in the future.

\section{Highlights}

1- Research trends in forward osmosis technology in the last 20 years.

2- Most important research areas are fouling, draw solution, and membrane development.

3- Increasing research activity is in organic matter treatment, recovery system of the DS and energy consumption.

4- The establishment of an energy- and cost-effective hybrid system is necessary to promote FO process.

\section{Keywords}

Desalination, Forward Osmosis, Wastewater, Draw Solution, Fouling. 


\begin{tabular}{|c|c|}
\hline 1. Introduction & 3 \\
\hline 2. Statistics of forward osmosis (FO) publications & 7 \\
\hline 2.1 Major industrial players of FO systems & 7 \\
\hline 3. Membranes, draw solutes and niche applications & 10 \\
\hline 3.1 FO membrane development & 10 \\
\hline 3.2 Draw solutes & 18 \\
\hline 3.3 Membrane fouling and mitigation & 23 \\
\hline 3.4 FO applications & 26 \\
\hline 3.5 Organics removal in FO process & 31 \\
\hline 3.6 FO process operation modes & 33 \\
\hline 3.6.1 Osmotic dilution & 33 \\
\hline 3.6.1.1 Fertilizer drawn forward osmosis (FDFO) & 34 \\
\hline $\begin{array}{l}\text { 3.6.2 Osmotic concentration-Regeneration of DS and energy } \\
\text { consumption }\end{array}$ & 35 \\
\hline 4 Challenges and future directions & 36 \\
\hline 5 Conclusions & 41 \\
\hline Acknowledgements & 42 \\
\hline
\end{tabular}




\section{Introduction}

The fast growth of population, industrialization, environmental deterioration, and economic evolution in the world have resulted in great demand for accessing freshwater $[1,2]$. The development of membrane technology is one of the most important technologies for water treatment fields. However, conventional pressure-driven membrane processes use high hydraulic pressure which accelerates the energy consumption and produces low water recovery [3]. It is known that water desalination processes consume a high amount of energy, and the global capacity totaling higher than 60 million $\mathrm{m}^{3} / \mathrm{d}$ [4]. In this respect, it is essential to explore a renewable-powered desalination system to reduce the energy demand and cost-effective system for water reclamation. Forward osmosis is an effective technology that does not need high hydraulic pressure as compared to the reverse osmosis process (RO). This leads to minimum energy consumption and low irreversible fouling propensity. Besides, it can be used to separate different contaminants achieving great water recovery rate [5]. Recently, research has focused on forwarding the osmosis process as an emerging energy-efficient technology for several fields involving wastewater reclamation, brackish water/seawater desalination, pharmaceutical and juice concentration, power production, and protein enrichment [6]. Although the FO process has various potential applications, the lack of appropriate FO membranes with efficient separation performance is a major drawback deterring the feasibility of this promising technology.

There is a number of membrane modules reported so far in the literature for the FO process, such as plate-and-frame, spiral-wound, Tubular, but the most common membranes are flat sheet and hollow fiber membranes. The commercially available traditional composite or asymmetric RO membranes used for FO operation composed of a thick porous support layer with $150 \mu \mathrm{m}$ and an ultrathin selective layer with $>1.0 \mu \mathrm{m}$ on the top [6]. It exists in two modules, flat sheet and hollow fiber which were fabricated via the phase inversion method. In 
comparison with hollow fiber, flat sheet membranes have a small surface area, simple structure morphology and can be easily prepared which allows for surface modification for both the selective and support layers [7]. In contrast, many issues appeared during the filtration test which is internal and external concentration polarization, which depend on the membrane orientation in the FO system. It caused low water permeation, poor salt rejection, and hydrolysis of the membrane $[8,9]$.

Therefore, the major challenge in the manufacturing of membranes is linking the functional property with the mass transfer of solute through the membrane. Also, the developed hollow fiber and flat sheet membranes suffered from the inevitable membrane-related concentration polarization (CP). When the support layer is against the draw solution, the transfer of water through the porous support layer results in dilution of the draw solution. Thus, internal concentration polarization (ICP) causes a drop in the concentration gradient created across the porous support layer, lowering the osmotic driving force, thereby reducing the water permeability through the membrane $[10,11]$. This effect depends mainly on the characteristics of the draw solution (DS) and membranes and operating conditions employed during the FO process [12]. The concentration polarization due to the accumulation of solute on the membrane surface or in the pores is known as fouling, which reduces the membrane performance. It causes either the formation of a cake layer on the membrane surface or poreclogging. This results in a sharp decrease in the water permeation, poor separation properties, and acerbating hydraulic resistance [13]. Even though increasing the flow rate of the draw solution may mitigate the $\mathrm{CP}$, this might be acerbating the concentration of the diluted draw solution thereby augmenting the energy consumption during the recovery process. Alongside this, the ICP effects can also reduce the energy efficiency and ultimate cost of the FO process. A prior study conducted a techno-economic analysis on FO coupled RO to minimize energy consumption. It was addressed that energy consumption can be lowered from 1.95 to 1.83 and 
$1.47 \mathrm{kWh} / \mathrm{m}^{3}$ when using RO-FO and FO-RO hybrid systems, respectively [14]. A group of researchers highlighted that increasing the length of the FO membrane module induced the permeate flow, the energy of recirculating the solution and the overall energy expenditure of the FO process [15]. To eliminate the above-aforementioned issues on the membrane performance, extensive research is in progress by implementing novel fabrication, surface modifications $[16,17]$, reinforcing additives, and so on $[18,19]$. The fundamental objectives in an FO process are high water permeation and selectivity associated with minimum reverse solute flux. Despite the above limitations, the research on the FO process has continued and the number of publications was increased on performance studies and various applications in the last decades. It is because the FO has started to be recognized as a promising technology in a wide application across different industrial sectors. The FO integrated other processes that have achieved specific application aims and efficient performance in some industrial applications [20].

The objective of this review is to perform bibliometric analyses on the general and specific research directions of the FO process and membranes from 1999 onwards. Science Direct database has been used to accumulate the total articles, book chapters, and books published across a diverse range of academic journals. Scopus database was selected to collect publications classified by subject areas and total publications across diverse countries. Thus, this review starts by outlining the main journals publishing papers on the FO process and membranes. It classified the total publications by subject area to provide an insight into the most significant research topic. Also, it highlights the recent progress in foremost research areas emphasizing the most significant ones that affect the performance of the FO membranes. These topics include draw solution, membrane fabrication and modification, fouling phenomenon, hybrid system, and energy consumption. Ultimately, more focus will be given to 
potential applications of the developed membranes for effective utilization of the FO process and will show further insight into future prospective.

\section{Statistics of forward osmosis (FO) publications}

Since 1999, there have been 7175 journal papers related to the FO process including 1522 journal papers (27\%) which covered different types of FO membranes. In general, there is an increasing trend in FO research from 1999 to now as described in Fig.1. The keyword topics searched in Science Direct were "Forward Osmosis Process" and "Forward Osmosis Membranes”. According to the Science Direct platform, the total number of publications is 7173 including review articles, technical papers, book chapters, books, conference proceedings, and others. The majority of documents were the technical papers regarded as 4365. However, the total number of papers fluctuated from year to year and then it steadily increased from 2012 to 2019. As shown in Fig.1 and Table.1, the number of articles published was classified by FO topics from 1999 to 2020, according to the Science Direct platform. These topics involved draw solution, membrane fabrication and modification, hybrid system, mathematical modeling, energy consumption, and techno-economic analyses. These keyword topics were also searched in Science Direct and Scopus because they were reported in most of FO publications. Fouling phenomenon presented the largest number of papers followed by draw solution, fabrication, and modification of FO membranes.

In Fig.2, the common membrane modules used in the fabrication and modification studies were hollow fiber and flat sheets modules. The largest number of review articles has dealt with fabrication and modification of hollow fiber and flat sheet modules corresponding 306 and 257. However, most of the technical papers published on the fabrication and modification of flat sheet modules corresponding to 949, while it decreased to 760 for hollow fiber modules. Research into the energy consumption of the FO process showed similar increasing trends from 
2007 to 2008 reaching 56 papers but it slightly declined in 2009. Afterward, the total number of research documents rose dramatically from 312 to 1127 in 2020. A large increase in the number of total research papers observed in the year 2019, reaching 147.

\subsection{Major industrial players of FO systems}

A number of industrial companies for FO systems and membranes exists globally which achieved significant process improvements. Fig. 3 shows a few companies worldwide offering commercial FO systems and FO membranes. A membrane manufacturing company, HTI Inc., has recently launched new products including the spiral-wound (SW) 4040 and 8040 FO elements made of cellulose triacetate (CTA). The number 4040 means that the module diameter is 4 in and the module length is 40 in. Another water-related company, Oasys Inc., has also marketed SW 8040 FO elements made of a thin-film composite (TFC) polyamide membrane [21].

Sterlitech offers two brands of forward osmosis flat sheet membranes for separations requiring low energy and low pressure. FTS $\mathrm{H}_{2} \mathrm{O}^{\text {TM }}$ flat sheet membranes are composed of cellulose triacetate (CTA) can be operated in the $\mathrm{pH}$ range 3-7 and offers maximum chlorine resistance 2 ppm posess 3 years of shelf life (https://www.sterlitech.com/ftsh2o-flat-sheet-membrane-ctafo-cf016-5-pk.html). Another brand of forward osmosis membrane is Aquaporin Inside ${ }^{\mathrm{TM}}$ membrane which is based on the aquaporin proteins which are $100 \%$ selective to water molecules. This Thin-Film Composite membrane is available both as a flat sheet and hollow fiber. Aquaporin Inside ${ }^{\circledR}$ HFFO modules are designed to be compact, lightweight and easy to install. HFFO28 modules have the same $0.2 \mathrm{~mm}$ fiber ID and feature $28 \mathrm{~m}^{2}$ of active membrane area. HFFO41 modules have the same $0.2 \mathrm{~mm}$ fiber ID and feature $41 \mathrm{~m}^{2}$ of active membrane area. HFFO14 $13.8 \mathrm{~m}^{2}$. Available from $0.6 \mathrm{~m}^{2}$ to $41 \mathrm{~m}^{2}$ surface area and with $0.15 \mathrm{~g} / \mathrm{L}$ reverse solute flux (RSF) (https://aquaporin.com/forward-osmosis-membranes/). Further, Aquaporin 
and Goldfinch, India, have signed a distribution agreement for the Aquaporin Inside ${ }^{\mathrm{TM}}$ forward osmosis technology within the fields of wastewater treatment and process application for industrial and commercial segments.

The Porifera FO membrane is ideal for research applications with $33 \pm 2 \mathrm{~L} / \mathrm{m}^{2} \mathrm{~h}(\mathrm{LMH})$ water flux in FO mode, Microorganisms Log Reduction Bacteria >8, Virus $>6$, Rejection Arsenic $>90.0 \%$, Boron $>80.0 \%$. PFO-9S is a lat-sheet commercial proprietary membrane module 63 $\mathrm{m}^{2}$ having a 2-11 operatoing p H range with 0.2 - 0.6 g/L RSF (http://www.porifera.com/). Berghof Membrane Technology GmbH, a leading manufacturer of tubular membranes has announced that it has formally signed a joint development agreement with Aquaporin A/S, the Denmark-based developer of biomimetic membranes wherein both companies will leverage their respective expertise in forward osmosis (FO) and tubular membrane technologies, to launch products targeted for high-strength industrial wastewater and food and beverage process streams.

Trevi Systems is an innovative forward osmosis company creating an energy-efficient method to desalinate at $1 / 3^{\text {rd }}$ the energy of current technologies. Trevi Systems use their proprietary membrane and unique draw solution that allows the draw solute to be separated from the recovered water using thermal heat (https://www.trevisystems.com/technology-). Another player a Forward Water Technologies (Canada) has developed a proprietary technology ("twophase" draw solute) that permits the commercial scale-up of forward osmosis to treat waste streams from several industrial sectors (https://forwardwater.com/technology-market/).

Osmotic Engineering (UK) provides in-depth technical consultancy and operational support for osmotically driven membrane processes and membrane brine concentration. Darco Water Technologies (Singapore) provides a portable FO briefcase, a more advance lab test system, and an FO/SWRO hybrid pilot system with a daily treatment capacity of 5-10 $\mathrm{m}^{3} / \mathrm{d}$. Also, the pilot is ideal for test-bedding of industrial wastewater treatment. In addition, the pilot can be 
used directly on the production floor for low volume production of valuables (https://darcowater.com/).

The evapEOs ${ }^{\circledR}$ process harnesses the principle of Engineered Osmosis developed by EDERNA. EDERNA's patented a draw solution for mild concentration by Forward Osmosis of products in the Food and Beverage industry. EDERNA's has collaboration with BLUE-Tec who will be the exclusive supplier of full-scale units in this segment for Europe. The evapEOs claims to achieve higher levels of concentration (targeted concentration factor) to be reached with maximum performance with 5 times less energy-consuming than single-effect evaporator and 10 times less energy-consuming than spray-drying (http://www.ederna.com/principle).

\section{Membranes, draw solutes, niche applications}

\subsection{FO membrane development}

FO membrane is the heart of FO applications, and the development of ideal membranes is an active area of research by both academia and many industrial companies. The manufacture and modification of FO membranes have gained immense importance over the past years [5]. FO system requires a semi-porous membrane capable of separating disintegrated salt species from the feed solution (FS), high penetrability, high solute rejection, and resistance to chlorine during chemical cleaning for a long-lasting [22]. Nonetheless, the conventional membranes demonstrated low water penetrability in the FO procedure [23]. It was highlighted hypothetically and practically that the mass transfer could be restrained because of the obstruction at the interface, which is corresponding to the support layer thickness, and an inverse correlation was observed with the porosity [24]. The resistance of solution diffusion displays a decrease in the osmotic pressure through the membrane and consequently expanding the effect of the internal concentration polarization (ICP). Most of the earlier works with commercial and fabricated membranes reported that the water flux is self-limited due to 
significant ICP effects when using high salinity draw solution [25]. Accordingly, changing the support layer structure is important to decrease ICP impacts on membrane efficiency.

Numerous research studies have been carried out on fabrication of CTA and TFC FO membranes using novel materials and additives, different polymers and concentrations, modifying the structure of the support layer via various fabrication methods and altering the characteristics of the selective layer [5].

Herein, Fig. 4 shows the research trend for fabrication and modification of the FO membrane that gradually increased over time between 1990 and 2020. Further, Fig. S1 (SI) shows the trend for both fabrication and modification displays a significant increase from only 58 reviews and technical records in 2010 to around 1005 review and technical records in 2020. However, the number of publications declined by 3 folds in 2008, after which it showed a growth trend in the subsequent years. After that, the number of research documents was doubled between the years 2013 and 2014 and again doubled between 2016 and 2017.

Conventional phase inversion techniques are used to fabricate FO membranes and with interfacial polymerization (IP) technologies thin-film composites membranes are prepared. The FO membrane exhibits high flux around 14.1 LMH when cast with a layer-by-layer (LBL) technique [26]. It is known that performance of the FO membrane mainly depends on the fabrication method [5]. The FO membranes are usually of asymmetric composite and are made of two separate layers. The top layer is a thin rejection layer with thin film (thickness of 100$200 \mathrm{~nm}$ ) which is combined with a bottom layer that is support layer (thickness of 100-200 $\mu \mathrm{m})$. The thin layer function is to provide selectivity whereas the support layer provides mechanical strength to the forward osmosis membrane [27].

The company Hydration Technology Innovations (HTI, Albany, OR, USA) has provided asymmetric cellulose-based membranes for FO for nearly 20 years [28] (Fig. 4). Furthermore, the commercial symmetric cellulosic membrane manufactured by HTI (Hydration 
Technologies Inc., OR) made of cellulose acetate or triacetate layer cast on the woven or/and nonwoven mesh. It is worth noting that this membrane performs better than conventional RO thin film composite (TFC) membranes for the FO process due to low membrane thickness of $>50 \mu \mathrm{m}$ and the absence of thick a fabric support layer [9]. In 2008, HTI patented commercial asymmetric CA/CTA FO membranes composed of a thin skin layer for salt separation (10-20 $\mu \mathrm{m}$ ) and a thicker porous scaffold layer (about $100 \mu \mathrm{m}$ thick) with a woven or non-woven mesh embedded within it [28]. Yet, the available commercial cellulose acetate membrane provides low permeability, low salt rejection, poor resistance to biological species, and limited chemical stability [5],[29] During the past years, several studies have been published on the formation of hollow fiber membranes specially designed for osmotically driven processes. To improve the FO performance, Yang et al. [30] developed a dual-layer PBI-PES hollow fiber membrane via a co-extrusion technique. This membrane consisted of on an ultrathin selective skin layer, fully porous water channels underneath, and a microporous sponge-like support structure. The prepared PBI-PES/polyvinylpyrrolidone (PVP) dual-layer membrane achieved a pure water permeability (PWP) of $1.74 \mathrm{LMH} /$ bar and an $\mathrm{MgCl}_{2}$ rejection factor of $87.2 \%$. The obtained water permeate flux in FO mode using $2 \mathrm{~mol} / \mathrm{L} \mathrm{MgCl}_{2}$ as a draw solution $14.8 \mathrm{~kg} / \mathrm{m}^{2} \mathrm{~h}$, was higher than those of the commercial RO membranes (AG, GE Osmonics, $2.5 \mathrm{~kg} / \mathrm{m}^{2} \mathrm{~h}$ (Miller \& Evans, 2006), but comparable to most commercial HTI FO flat sheet membranes (i.e., 12.9 $\mathrm{kg} / \mathrm{m}^{2} \mathrm{~h}$ for FO experiment [31].

Generally, high osmotic flux and low structural parameter values were achieved for nanofiber membranes, making it a suitable method for the fabrication of FO membranes. Song et al. [25] prepared a novel electrospun nanocomposite FO (NC-FO) membrane with a scaffold-like nanofiber support layer of $50 \mu \mathrm{m}$ thickness that achieved 37.8 LMH flux and 97\% salt rejection as compared to commercial HTI-FO membrane of the same thickness (6.5 LMH flux and 92 \% rejection). Fang et al. [32] fabricated novel composite double-skinned Poly(amide-imide) 
(PAI) hollow fiber membranes for FO. In this case, two selective skin layers were integrated in each side of an ultrafiltration (UF) hollow fiber substrate via IP and chemical modification to yield a PA RO-like inner skin layer and a positively charged NF-like outer skin layer. The hydrophilic nature of the two skin layers reduced the contact angle of the membrane from $80^{\circ}$ for PAI hollow fiber substrate to $46^{\circ}$ for the composite FO membrane. The prepared doubleskinned composite hollow fiber membrane exhibited a high Pure water permeability of 2.05 $\mathrm{LMH} /$ bar and $85 \% \mathrm{NaCl}$ rejection at 1.0 bar pressure. The performance of this membrane was superior to commercial HTI FO membranes as well as other double-selective layer membranes reported in the literature.

Liu et al. [33] fabricated a freestanding ultrathin reduced graphine oxide (GO) membranes, with thicknesses down to $17 \mathrm{~nm}$. The FO performance of the freestanding rGO membrane with a thickness of $100 \mathrm{~nm}$ achieved $57 \mathrm{LMH}$ water permeability. This is approximately five times the water flux of the commercial cellulose triacetate (CTA) FO membrane (Hydration Technology Innovations (HTI)) under the same conditions.

In 2010, Oasys (Osmotic Applications and Systems) launched the world's first thin film composite polyamide-based spiral wound FO membrane element [34]. In 2012, the TFC polyamide spiral wound module (8” diameter, $15 \mathrm{~m}^{2}$ area) manufactured by Toray Industries, Korea having around $50 \mu \mathrm{m}$ thickness demonstrated 9 LMH/bar water permeability, $85 \%$ red sea salt rejection [35]. The packing densities in the spiral wound FO module are obviously less than spiral wound RO modules. This is due to requirement of total thinckness of spacers between membrane layers to accommodate the high cross flow of fluids on both side of FO membranes. Further, spiral wound FO modules are more popular in desalination and less attractive in industrial water treatment as more fouluants are present [36]. In 2014, Toyobo’s hollow fiber CTA FO membrane demonstrated 10 times area compared to the flat sheet membrane for the seawater desalination and wastewater treatment. This membrane offers 
energy saving for seawater desalination as the need for a high-pressure pump and piping can be eliminated [37].

Porifera developed plate and frame modules in 2014 under the commercial name of PFO elements. Porifera PFO elements are claimed to offer $63 \mathrm{~m}^{2}$ membrane are per module, 2-11 operating $\mathrm{pH}$ range, around $9 \mathrm{LMH}$ water flux and 0.2 - 0.6 g/L RSF [38, 39]. Tang et al. [38] addressed that membranes composed of aquaporin protein function showed very high permeability and salt rejection. The Aquaporin Z (AqpZ) based biomimetic membranes could produce $601 \mathrm{LMH} /$ bar permeability which is doulble than commercially available seawater RO membranes. Nevertheless the bottleneck would be to scaleup these nanoscale elements (the aquaporins) to $\mathrm{m}^{2}$ dimensions suitable for industrial applications [40].

The Aquaporin Inside flat-sheet membrane is the first commercially available thin-film composite (TFC) FO membrane to incorporate aquaporin proteins into its polyamide-based selective layer. In FO mode, the tested membrane achieved 8.8 LMH water flux with low RSF around $4.0 \mathrm{~g} \mathrm{~m}^{-2} \mathrm{~h}^{-1}$, respectively having $630 \mu \mathrm{m}$ structural parameters similar to the existing commercial FO membrane [41]. Recently, the Aquaporin Inside ${ }^{\circledR}$ HFFO14 module made of polyamide thin film composite (TFC) is designed for Forward Osmosis (FO) applications. This membrane is capable of rejecting difficult contaminants and preserving valuable components offers a very high packing density [42]. More recently, a TFC-FO membrane demonstrated 4.7 times higher water flux than the commercial CTA-TFC-FO membrane. For membrane fabrication, the wet-spinning method was used with interfacial polymerization and polyamide (PA) active layer was coated onto a CNT hollow fiber scaffold (CNT TFC-FO) [43].

A wide range of polymers and monomers for the support layer and selective layer were used for FO membranes were discussed in detail in our previous work [5]. Reports outline several polymers used for manufacturing the support layer. Out of the total research documents in this topic, the alteration of the support layer using cellulose acetate and polysulfone materials 
showed the largest percentage of publication (Fig. S2 (SI)). While the trend in research documents related to the modification of the support layer using cellulose triacetate, polyethersulfone, Polyvinylidene fluoride, Polyacrylonitrile, Sulfonated polysulfone is increasing, the development of commercial membranes is still low. The most common robust additives/fillers used for the fabrication and modification of FO support layer are silica material, carbon nanotube material, graphene material, Zeolite material, silver nanoparticles, sodium alginate, zinc oxide nanoparticles, nanoclay, carbon nitride, titania and nano-wires (Fig. S3 (SI)). The choice of filler could be attributed to the special properties of these materials and their benefits on the improvement in the membrane performance. It has been stated that silica nanoparticles are chemically and thermally stable, abounded material and cheap, compatible with support layer polymer, easy adjusting the particle and pore size [44]. Silica material was progressively competing with the other materials. For example, researchers incorporated mesoporous silica nanoparticles into Polyacrylonitrile (PAN) suspension to improve the water uptake capacity [45]. The final support layer was deposited on to the PET nonwoven fabric while the PA was synthesized by interfacial polymerization. The membrane fabricated by this method exhibited outstanding performance achieving 7-fold improvement in water permeability due to its porosity and ability to uptake a high amount of water and 3.5-fold improvement in $\mathrm{NaCl}$ rejection rate and lowered ICP effects. Additionally, Choi et al. [46] blended functionalized multi-walled carbon nanotube into cellulose acetate polymer via phase inversion. The dope polymer was viscous leading to compacted membrane structure. However, the best performing membrane, including $1 \%$ fCNT exhibited the greatest water flux which increased by $50 \%$ as compared to the pristine membrane. This can be ascribed to the high hydrophilicity due to carboxylic groups in functionalized carbon nanotube as the contact angle was $58^{\circ}$ versus $66^{\circ}$ for the pristine membrane. Besides, this optimum membrane showed less 
fouling propensity towards sodium alginate, and the decline in the water flux was lowered by $57 \%$ over the pristine membrane.

Apart from this, the modification of the selective layer to develop highly selective membranes towards different types of contaminants. Several industries imposed designing perfect membranes to serve seawater/brackish water desalination, wastewater reclamation, pharmaceutical and agricultural applications, etc. Over the period reviewed, modification of the selective layer is an emerging topic under the development area. It was observed that researches on altering the polyamide selective layer had grown considerably. This can be attributed to increasing researches on modifying FO membranes to impart functionality to the interface of polymer membranes such as mitigating fouling, improving hydrophilicity, and selectivity. Also, reinforcing the polymeric membranes with different types of nanofillers contributed to high hydrophilicity and improved selectivity [47]. A further improvement in the membrane hydrophilicity, water permeability, selectivity, and stability can be accomplished by modifying the membrane using various nanomaterial additives, grafting, and coating methodologies $[48,49][50,51][52,53]$. As polyamide is the most widely used selective layer for modification research, a possible method to minimize fouling is surface alteration by grafting a zwitterionic polymer brush via atom-transfer radical polymerization (ATRP) [54]. The morphology of the new selective layer was greatly modified, showing low roughness, good hydrophilicity, and reduced charge density. This caused low adhesion of foulant, e.g., proteins and bacteria on the selective layer surface, leading to lower foulant-membrane interaction forces by 1 order of magnitude as compared to the pristine membrane. In FO fouling test, the water flux exhibited lower flux reduction by 3 times to those pristine membranes against 100 mg/L BSA, sodium alginate, and SRNOM feed solution. Even though the zwitterionic coating efficiency decreased slightly over long-term operation due to the interaction between new and already deposited foulants on the selective layer, it still results in delayed organic fouling. 
Another research is embedding $\mathrm{Al}_{2} \mathrm{O}_{3}$ nanoparticles into both the Polysulfone support and Polyamide active layers to additional create water channels in the substrate leading to increment in mass transfer and water permeability [55]. It was found that the addition of (0.5 \%wt) $\mathrm{Al}_{2} \mathrm{O}_{3}$ NPs improved the substrate morphology, which involved high porosity and pore size distribution and the finger-like structure was formed. Also, the structural parameter was decreased significantly, resulting in lower ICP impacts. Also, roughness and thickness of the selective layer became higher arising from larger "leaf-like” structures and NPs aggregation. It was expected that the higher roughness, hydrophilicity and large surface area of the active layer caused high water flux, whereas the salt leakage was reduced. Overall, the modified TFN membrane presented great FO performance and stability over long term operation.

Surface modification methods of FO membranes are a key parameter for the success of the FO process. Among these methods, layer by layer has been used widely to fabricate thin nanoscale film on the support layer due to easy to tun up and superior process for surface modification [56]. It is realized that the thickness of this selective layer created on the support layer can be adjusted easily to minimize the hydraulic resistance and achieve maximum water permeation and selectivity [57]. Besides, the surface charges can be converted on the positive or negative outermost layer to improve the function of the membrane in specific applications. Although the stability of the thin film was weak in earlier works, it was proved that the thin film crosslinked with robust materials was more stable in recent studies [26, 57]. Several studies confirmed that the FO membrane modified LbL showed enhanced performance towards fouling, scaling, ICP impacts, and selectivity. For example, when the FO substrate was exposed to 3 layers of Chitosan (polycation) and polyacrylic acid (polyanion) polyelectrolytes crosslinked glutaraldehyde via L-b-L assembly [58]. The resultant was studied in terms of surface morphology before and after the L-b-L treatment and the performance. It was observed that the selective layer 3LbL appeared thin and in the form of the sponge-like structure might be caused 
by the chitosan and polyacrylic acid as polyelectrolyte layers. The substrate hydrophilicity improved, which correlated with the increment of the water flux and excellent selectivity. Thus, a great water flux was achievable for FO and PRO configurations and the salt reverse diffusion was greatly reduced due to the dense and uniform 3LbL active layer. This signifies the importance of research in FO membrane modifications which obtained immense importance in the last decades.

Nevertheless, more works are needed to deal with the limitations like the trade-off effect among permeability and selectivity. Further researches on modifications using potential materials should be explored in the sense that they offer the perfectly selective property for various contaminants with great water permeation and rejection rate. Finally, the optimization of largescale membrane modules comparative pilot plant studies is important to understand the feasibility of membranes for different applications before commercialization.

\subsection{Draw solutes}

The type of draw solution plays an important role in the FO process, influencing FO membranes and performance; for this reason, selecting an ideal draw solution is necessary [59]. As shown S4 (A) (SI)), the evolution of draw solution remained steady and the total of articles was 173 in the first decade (1999-2009) while many more articles were published of about 3178 in the subsequent years. In the period 2002 to 2006, the total quantity of publications on draw solution was declined, and then it was increased significantly to 163 in 2013. Again, it was dropped by 10\% in 2014, after which it was incremented to 404 documents in 2019. Besides, ongoing research landscape of FO technology-focused on the draw solutions, which gained popularity after 2007 and draw solution relevant publications shown the third important publication growth.

The draw solution is the driving force in FO desalination that plays a significant role in the FO system efficiency. The draw solute must be able to produce greater osmotic pressure than the 
osmotic pressure of the feed solute to drag water flux through the membrane. The best performing draw solution should contain the small size and charged ions, a low molecular weight, a low viscosity, non-toxic. Small ion size of draw solution dispersed well in the solvent and showed a high diffusion rate, thereby hampering the mass transfer resistance across the membrane (e.g., $\mathrm{NaCl}$ [60]. Recently it was recommended that when selecting a draw solution for FO application, the chemical structure and simple replenishment method are crucial parameters like polyelectrolyte DS (Table 2). The monomer composition, network structure, and hydration of the hydrogels draw solution are also important properties [61]. Table 1 describes the general DS characteristics affecting FO process performance. Currently, increased efforts have been dedicated to developing a diverse range of draw solutions. The total number of reviews and technical papers published on various types of draw solutions reached 1679 from 1999 to 2020.

Fig. 5 shows the evolution of the draw solution with time. The most common categories among the draw solution with regard to publication proportion includes gas and volatile compoundsbased draw solution, organics-based draw solution, inorganics-based draw solution and functionalized nanoparticles-based draw solution (see Fig. S4 (A) in supplementary materilas). Earlier, volatile solutions, such as sulfur dioxide, were utilized as draw solute in 1960s and could be recovered by a heating gas stripping operational condition [27]. The gas and volatile compounds such as alcohol as draw solutions category totaling $13 \%$ of the publications. In contrast, these compounds are not suitable for the FO process because of low water flux and the high diffusion rate, which induces reverse solute flux. Also, it is one type of nutrient that may accelerate biofouling on the surface of the FO membrane [62]. Over the past decades, organic compounds particularly fructose and glucose solutions have been tested as DS, especially for seawater desalination [63]. This unique characteristic of surfactants possessing constant and moderately high osmotic pressure at concentrations above the Critical Micelle 
Concentration make it an interesting group of organic draw solutes. The surfactants as a DS achieved stable water flux in OMBR which implies that this DS should be explored in future study [64]. McCutcheon et al. [65] investigated thermolytic solutions such as ammonia carbonates are considered as the promising DS for desalination applications. Due to very high osmotic pressure of this DS very high flux was anticipated however ICP adversely affected process performance and high RSF and high biofouling was reported due to hgh diffusivity of ammonia also a nutrient [62].

However, the most widely used draw solutions are inorganic salts (e.g. $\mathrm{NaCl}$ ) and simple organic salt (e.g., Sugar) reaching 20\% for each out of the total publications. A diverse range of draw solution have been studied including $\mathrm{MgCl}_{2}, \mathrm{Na}_{2} \mathrm{SO}_{4}, \mathrm{CaCl}_{2}, \mathrm{Ca}\left(\mathrm{NO}_{3}\right)_{2}, \mathrm{KCl}, \mathrm{MgSO}_{4}$, $\mathrm{KNO}_{3}, \mathrm{KSO}_{4}, \mathrm{NH}_{4} \mathrm{HCO}_{3},\left(\mathrm{NH}_{4}\right)_{2} \mathrm{SO}_{4}$, and others [66]. In 2007, Adham, Oppenheimer, Liu and Kumar [67] proposed the use of ethylenediaminecore dendrimers with sodium succinamate terminal groups and pentaerythrityl core dendrimer with sodium carboxylate terminal groups as a novel DS for dewatering RO concentrate. Dendrimers possess nanostructures and systematically manufactured to carry molecluels inside their voids or attached to the surface and they have very high osmotic pressure as well as easy to regenerate employing ultrafiltration. Zhao et al. [68] evaluated poly(amidoamine) having $-\mathrm{COONa}$ bonding as draw solute for seawater desalination in a forward osmosis and membrane distillation (FO-MD) hybrid process. At the same solution concentration, PAMAM-COONa of higher molecular weight showed lower osmotic pressure and water flux but smaller reverse solute flux.

Other researchers developed magnetic nanoparticles as a draw solution for the FO system. In principle, when magnetic nanoparticles with large sizes are dissolved in DI water to make a draw solution, the solution became inhomogeneous. As a result, the osmotic pressure would not be high as inorganic salt draw solutions. On the contrary, if the particle size is larger than the membrane pores, the RSFmight not be detected. It must be noted that the aggregation of 
the nanoparticles is still a major challenge, but they can be re-concentrated easily and reused in the FO process. To avoid this aggregation issue, $\mathrm{Na}$ and co-workers [69] synthesized novel hydrophilic citrate coated magnetic nanoparticles (cit-MNP1 and cit-MNP2) via a coprecipitation method and dispersed in water to form a draw solution. $\mathrm{Fe}_{3} \mathrm{O}_{4}$ nanoparticles are spherical particles and their diameter ranging from 3 to $8 \mathrm{~nm}$ and have high negative charges and charge density on the surface. To prevent aggregation, a hydrophilic citrate coating was applied on the surface. The carboxylic groups on citrate could bind to Fe ions, which resulted in the incorporation of these groups on the surface of the Fe3O4 nanoparticles. Among other coatings, the water flux of cit-MNP2 was impressive approaching 17.3 LMH upon using 20 mg/L MNP, but membrane fouling was an issue in the FO operation. On the other hand, there was a remarkable drop in the water flux elicited by an interaction between the cellulose material of the membrane and magnetic nanoparticles. This is because the agglomeration of the nanoparticles cannot be averted using the ultrasonic method. It was found that pore size distribution and hydrophilicity of the CTA membrane influenced the performance of the nanoparticles DS.

Li et al. [70] was the first to study the potential of hydrogels as draw solutes. Hydrogels are crosslinked hydrophilic polymers with water entrapped within the network are capable enough to produce very high water flux in FO application. Unfortunately, water recovery from the hydrogel is too poor. The imbalance between swelling de-swelling rates of the thermally responsive hydrogels was a major obstacle. Cai et al. [71] later synthesized new hydrogels based on thermally responsive polyionic liquids, and the water flux more than quadrupled that attained by PNIPAm based semi-IPN hydrogels.

Mainly inorganic fertilizers are attractive option as a DS for seawater and wastewater extraction when the FO is considered as a standalone process and diluted DS can be used directly for fertigation. Phuntsho et al. [72] evaluated nine inorganic fertilizers in FO application for flux 
and RSF measurements. Urea exhibits highest RSF among all fertilizers and it was suggested that urea should be avaoided in blended fertilizer. The highest performance ratio was found for $\mathrm{NH}_{4} \mathrm{NO}_{3}>\mathrm{KCl}>\mathrm{NH}_{4} \mathrm{Cl}$.

Stone et al. [73] is the first to introduce switchable polarity solvents (SPS) as drawsolutes based on tertiary amines molecules. The amine molecules solubility changes according to carbon dioxide concentration and the hydrophobic amine becomes hydrophilic and ionizes upon reaction with $\mathrm{CO}_{2}$, to produce a draw solution with a very high osmotic pressure (Fig. 6). Regeneration can be done by moderate heating using low garde waste heat or with nitrogen purging when $\mathrm{CO}_{2}$ is removed and the amine restores to its hydrophobic non-ionic neutral state, facilitating phase separation from water. Final product water is polished by RO. However, few of the limitations are the SPS are not considered thermolytic like ammonium carbamate and another issue could be their compatibility with FO membranes as small molecular amines tend to swell and damage themembrane rejection layer and deteriorate its selectivity.

It is wellknown that nanoparticles as a draw solute could theoretically have very low RSFdue to its size. Alternatively, ionic species such as $\mathrm{Na}^{+}$paired carbon quantumdots attached to the surface of nanoparticles help increase the osmotic pressure of the draw solutions were capable to generate a high water flux when seawater was a feed solution [74].

The minimum percentage of publications was assigned to thermo-responsive copolymer and stimulus-responsive nanoparticles. Recently, a series of stimuli-response hydrogels were proposed as DS in FO. This novel type of hydrogels-driven FO process employing the solar energy for the DS regeneration have been attracting more and more attentions. Especially, the light or thermoresponse hydrogels can release fresh water when it is exposed to sunlight, because of the structure's own shrinkage. For instance, the light or thermoresponse hydrogels can take up enough water under the temperature of maximum volume phase transition and dewater at temperatures above the volume phase transition temperature [75]. It can be implied 
that the characteristics of these draw solution had a great influence on membrane performance. For example, the particle size and size distribution of a hydrogel can reduce the water permeation through the membrane. The membrane effort to produce improved water flux when using a larger particle diameter-based draw solution. However, some draw solutions had small particle diameter, which induced the passage of tiny molecules through the larger membrane pores resulting in high RSF [76]. As the copolymer draw solution had high molecular weight, large particle size, and high viscosity, the membrane would generate minimum water flux at the expense of energy consumption needed for pumping highly viscous draw solute and additional pressure drove regeneration method. Apart from the above concerns, it may result in high energy consumption and operating cost to produce drinking water and recycle the diluted draw solution, which is still a challenging issue for all draw solutions. To that end, the behavior of the thermo-responsive draw solute tends to diminish because of the mutual interference of network structure. It was addressed that the expanded network hampered the swelling pressure. However, there is still a lack of information on the estimated energy consumption and operating cost for each thermo-responsive polymer for comparison.

\subsection{Membrane fouling and mitigation}

Among the key areas of research is the fouling problem in wastewater treatment and desalination. The onset of membrane fouling depends on the mass transfer mechanism which reduces the efficiency and lifetime of the membrane. Many aspects of mass transfer cause the adhesion of foulants and adsorption of various species onto the membrane surface and pore resulting in membrane fouling [77]. There are different types of foulants in the feed solution such as colloidal or particulate matter, inorganic components, dissolved organics, microorganisms and microbial species, and chemical reactants [78, 79]. Membrane fouling causes the formation of cake layer or pore blockage and therefore minimize water permeation 
and selectivity [13]. Even though fouling can be mitigated via optimizing the process parameters and effective cleaning methods or using low-fouling membrane materials, it is impossible to be prevented as the feed solution includes certain components. Therefore, a pretreatment method of the feed solution and chemical cleaning are required, which increase the cost and energy consumption of FO operation. The mitigation of membrane fouling is essential specially during the treatment of wastewater as biological pollutants induce biofouling. By observing the growth trend for continuous researches in the membrane fouling it was found that the number of records was minimum from 2000 to 2008, after which it became larger in the following years. In 2014, the number of the review and the technical papers increased by the double reaching 165 and there was a constant increase in the publication in the next years. After that, the number of the review and the technical papers was increased simultaneously each year totaling to 1868 (2014-2020) out of 2413. Most of the publications have dealt with membrane fabrication and modification to minimize biofouling totaling 831 of the review and the technical papers over the period studies.

For example, membrane modified zwitterion-silver nanocomposite was fabricated to mitigate biofouling [80]. The silver nanoparticles had effective antimicrobial activity. When they were impregnated in the membrane, the biofouling resistance was improved considerably. The properties of the new membranes were enhanced, showing long-term minimum biofouling propensity and antifouling property could be regenerated easy. As the bacterial growth on the membrane surface was reduced, the water flux was incremented remarkably by two folds along with excellent selectivity. This can be attributed to the less deposition of microorganisms on the surface allowing high contents of water on the surface. The presence of water molecules on the surface resulted in lower adsorption capacity between the microorganisms and the membrane surface. 
Adding to this, increasing the hydrophilicity is an effective approach to minimize fouling and augmenting water flux without sacrificing the reverse solute flux. To improve the membrane hydrophilicity, incorporating hydrophilic functionalized nanomaterials into the membrane matrix [49] or coating the surface [81] were effective methods. One study found that coating the membrane surface by polydopamine and grafting poly (ethylene glycol) lead to high hydrophilicity and antifouling property [82]. The performance of the modified membrane was assessed in a submerged osmotic membrane bioreactor (OMBR) and compared with the neat CTA membrane. The modified CTA membrane had better hydrophilicity as the contact angle was decreased from $91.0 \pm 2.0$ to $67.2 \pm$ 8.6. The antifouling ability of the new membrane was improved significantly because the bioinspired coating reduced the adhesion of the biofouling layer on the membrane surface. Although the water flux was lower than that for the neat membrane due to the additional resistance caused by the coating layer, the selectivity was enhanced remarkably for the new membrane.

Other research papers covered the correlation between fouling behavior and the critical water flux. It is recognized that the considerable fouling formed when the water flux exceeded a critical value. A study by Zou et al. [83] investigated the effect of draw solution concentration, feed composition, and utilizing a feed spacer on the membrane fouling in the FO process. In this work, a microalgae Chlorellasorokiniana as the fouling agent was added into the synthetic surface water as the feed solution. The results indicated that the membrane performance was affected by serious micro-algal fouling at high water flux above the critical value. The critical water flux was determined at lower than $10 \mathrm{LMH}$, and the critical draw solution concentration was higher than $0.25 \mathrm{~mol} / \mathrm{L} \mathrm{NaCl}$ solution. Furthermore, the addition of $\mathrm{Mg}^{+2}$ into the draw solution reduced the critical flux but acerbated fouling due to reverse solute diffusion. Also, higher contents of $\mathrm{Mg}^{+2}$ in the feed solution increased membrane fouling and less reversibility. However, the presence of spacer in the feed side enhanced the initial water permeation, critical 
water flux (from 28 to $52 \mathrm{LMH}$ ), and antifouling property. Alongside micro-algal fouling became partially reversible by a physical cleaning of the membrane.

It was concluded that the longstanding problem of fouling hampers the success of the FO process and membrane efficiency. Fouling is mostly reversible, and the initial flux can be recovered using physical cleaning at a high flow rate. On the other hand, irreversible fouling can be reduced by chemical cleaning. However, cleaning is ineffective if foulants deposited in the porous support layer. Also, in-depth and systematic researches are essential to understand the fouling mechanism during long term operation and industrial scale. It is important to conduct an in-situ real-time fouling assessment for FO advancement and preventing fouling. Pathak, Fortunato, Li, Chekli, Phuntsho, Ghaffour, Leiknes and Shon [84] evaluated the biofouling development on forward osmosis membranes employing optical coherence tomography (OCT) technique. On-line in-situ real-time monitoring of biofilm growth on a flat sheet cellulose triacetate forward osmosis (CTA-FO) membrane was conducted for 21 days. In earlier studies, model foulants used was humic acid or alginate (BSA) or silica components. Therefore, real wastewater or seawater should be tested be in the FO process to obtain reliable results for large scale operations. More studies are required to examine novel antifouling materials as most of the nanomaterials are expensive, and the synthesis procedure is timeconsuming.

\subsection{FO applications}

Forward osmosis application has a wide arrays that includes lab-scale experiments to full-scale implementation involving osmotic hydration bags, in food and beverage industries, wastewater reclamation using osmotic membrane bioreactor, brackish water/seawater desalination, pharmaceutical and juice concentration, fertigation in agriculture, power production and other 
industrial processes, zero liquid discharge (ZLD) concept and finally industrial scale-up (Fig. 7) $[85,86]$.

The concept of hydration bags was developed for military, recreational, and emergency relief situations when reliable drinking water is scarce or not available [87]. In 1975 for the first time, the forward osmosis process was commercially used to make an emergency drink from a seawater, brackish or impaired water source the process was originally developed for the US military. A sugar solution (dextrose and fructose) is contained within a bag that acts as a semipermeable FO membrane [88]. In the last decade, MacCutcheon et al. [89] investigated the performance of the FO process using a recyclable solute composed of ammonium bicarbonate draw solution to extract water from a saline feed water. Due to the very high solubility of DS in water high osmotic pressure and high flux were achieved. The diluted DS can be easily separted by moderate heating (thermal separation). Forward osmosis (FO) has been used as an alternative to the thermal processing in food processing to save the sensorial and nutritional properties of the final product [90].

Petrotos et al. [91] produced better quality concentrated fresh tomato juice of $16^{\circ}$ Brix using a modified FO membrane than by vacuum evaporation in terms of intense red colour and stability. Other emerging area for FO in food processing includes tea leaves extraction, dewatering whey in the dairy industry and concentrationg liquid food.

Marques et al. [92] reported that FO could be a promising option in tea extraction compared to conventional heating route or spray drying. FO can retain the taste and aroma of the tea extract and thereby produces quality tea extracts. More recently, the Commonwealth Scientific and Industrial Research Organisation in collaboration with the membrane manufacturer Porifera, investigaed novel FO based process for concentrating liquid foods. This novel process claims to reduce OPEX by $60 \%$ as compared to the heating route and reverse osmosis will bring breakthrough in the Australian food industry [93]. 
In 2009, a laboratory-scale OMBR was presented by Achilli et al. [94], and thenafter many more reports on OMBR were published. OMBR has advantages as a low and reversible fouling propensity, minimum cleaning cycles, and energy-efficient process. In recent years one of the modification of OMBR the baffled OMBR was evaluated for simultaneous nitrification and denitrification and organic micropollutant removal [95, 96].

In 2011, Phuntsho et al. [72] came up with a novel concept of low energy desalination using fertilizer drawn FO wherein desalinated water can be directly used for fertigation. By using the FDFO process the end result is a diluted fertilizer solution for direct use without the need for the RO regeneration step making it less energy-intensive process.

Modern Water (UK) has developed and deployed a forward osmosis as a pretreatment to reverse osmosis desalination process on a commercial scale. To make the high-quality water Modern Water's Manipulated Osmosis Desalination (MOD) process integrates the FO system in a single cycle with a regeneration system. As shown in the Fig. 8 (a), fresh water permeates through the FO membrane into the concentrated draw solution in the FO system. The diluted draw solution is then "regenerated” in the RO system producing fresh water [97]. In June 2011, Modern Water was awarded the contract worth US\$ 650,000 to build and operate a $200 \mathrm{kLD}$ FOD plant by Oman's PAEW. Modern Water says it is the world's first commercial FO desalination plant and the group’s second plant in Oman [98, 99] (Fig. 8 (b)) .

Inversely soluble polymers may also be used as a draw solution, which on heating become less soluble and maybe partially separated from the water using a coalescer, followed by subsequent membrane treatment of the product stream to remove any residual draw solute. TreviSystems [100] uses a low molecular weight copolymer diol solute as the draw solution and is illustrated in Figure 9. The seawater is pretreated by an UF process, and then passes through the FO membrane. The diluted draw solution is heated by the heat exchangers prior to separation. The water is separated from the draw solution by a coalescer and then it is pumped to the NF for 
further purification and stored in a collection tank. The inversely soluble polymers used in this process as a DS, which on heating become less soluble and maybe partially separated from the water using a coalescer, followed by subsequent membrane treatment of the product stream to remove any residual draw solute [88].

The FO pretreatment process was used as a pretreatment for the MSF plant [101]. The target was to decrease the salinity of the feed solution thereby alleviating scaling. The MSF process consists of a series of "stages" ranging in temperature (from hot to cold) and pressure (from low to lower), as illustrated in Fig 10. Circulating seawater provides the condenser coolant in individual stages and is heated as it passes through the system. At the heating section, additional heat is transferred to the seawater stream (typically raising the temperature up to $110^{\circ} \mathrm{C}$ ) and it then enters into successive stages with lower temperature and pressure. Due to the gradually reduced (lower than atmospheric) pressure in each stage, the seawater immediately evaporates (flashes) upon entering stages. As per the report [101], one of the biggest challenges in thermal desalination processes is scaling (precipitation of salts such as calcium sulfate as well as other sulfates and carbonates). Calcium sulfate, for example, precipitates above $115^{\circ} \mathrm{C}$, which limits the top brine temperature and thus the efficiency of the distillation process. As a consequence, a substantial fraction of the OPEX costs in large-scale MSF plants is taken up by anti-scaling chemicals.

ZLD systems are being employed to meet increasingly stringent regulations for difficult-totreat wastewaters, or in situations where water scarcity demands water recycling and reuse [102]. Ultra-supercritical coal-fired power plant at the Changxing Power Plant in Zhejiang Province is one such company impacted by new Air pollution legislation in the People's Republic of China apply strict limits to NOx, SOx, particulate matter, and Hg discharges and effectively mandate electrostatic precipitation and flue gas desulfurization (FGD). A wastewater treatment plant was required to treat a combined waste stream, including the FGD 
blowdown wastewater and cooling tower blowdown [34]. Oasys Water and its Chinese partner were selected to deliver the world's first commercial application of Forward Osmosis (FO)based ZLD at the state-of-the-art Changxing coal-fired power plant (650 kLD capacity) (Fig 11). Oasys provided its ClearFlo Membrane Brine Concentrator (MBC) system and preconcentrating reverse osmosis (RO). At the same time, Beijing Woteer supplied physicchemical filtration, ClearFlo Complete ion exchange pretreatment, and a crystallizer package [103]. This system using RO to concentrate mixed wastewater from flue-gas desulfurization and cooling tower blowdown up to $60,000 \mathrm{mg} / \mathrm{L}$. Further concentration, up to $220,000 \mathrm{mg} / \mathrm{L}$ or above, is then achieved using a draw solution $\left(\mathrm{NH}_{3} / \mathrm{CO}_{2}\right)$. Finally, FO brine is sent to a crystallizer for further concentration. This process produces water with a solute concentration of $<100 \mathrm{mg} / \mathrm{L}$ that is recovered and reused in the boiler $[102,103]$.

Wünsch et al. [104] treated secondary effluent from a real wastewater treatment plant of a chemical industry employing FO which was pre-concentrated by RO. 1 mol/L each $\mathrm{NaCl}$, $\mathrm{Na}_{2} \mathrm{SO}_{4}, \mathrm{MgCl}_{2}$ DS were examined and corresponding reverse flows are investigated. $\mathrm{MgCl}_{2}$ outperform as a DS in terms of highest flux and less RSF. Singh et al. [105] evaluated the concentration of distillery wastewater by forward osmosis (FO) using aquaporin biomimetic membranes and magnesium chloride hexahydrate as draw solution. The authors reported a $90 \%$ rejection of melanoidins, $96 \%$ antioxidant activity and $84 \%$ COD was obtained with melanoidins a key color compound with antioxidant property used as a feed. Succinic acid is an inportant industrial chemical.

Law et al. [106] examined FO performance in separation and concentrations of succinic acid from its fermentation broth in the biological production process. In this process, $67 \mathrm{~g} / \mathrm{L}$ succinic acid and real sea water were used as a DS. Flux variation was observed in the range 0 to $4.8 \mathrm{LMH}$ and strong succinate rejections at higher $\mathrm{pH}$ above its $\mathrm{pKa}$ value (5.64) were 
obtained. In recent years resource recovery from various industrial processes and sewage treatment plants gaining more interest among researchers.

Luján-Facundo et al. [107] evaluated perormance of industrial effluent as a draw solution in OMBR treating simulated wastewater. The $\mathrm{SO}_{4}{ }^{-2}$ and $\mathrm{NH}_{4}{ }^{-\mathrm{N}}$ enriched industrial wastewater as a DS exhibited a higher RSF, but also a less severe fouling and a higher the osmotic pressure difference in comparison with the $\mathrm{NaCl}$ solution.

In another FO study, Soler-Cabezas et al. [108] evaluated the recovery of nitrogen and phosphorus of the anaerobically digested sludge centrate by FO using a residual stream from an absorption process for ammonia elimination as a DS that possesses high osmotic pressure. The absorption tower effluent as a DS enhanced the ammonium nitrogen concentration in anaerobically digested sludge centrate due to its RSF in the FO process. Phosphorous cannot be concentrated because of its spontaneous precipitation as calcium phosphate during the FO process.

Gwak et al. [109] suggested an attractive industrial application of forward osmosis (FO), for precious metal recovery from the printed circuit board manufacturing industry. Palladium can be recovered as Pd containing wastewater as FS was concentrated up to $90 \%$. In this process Nickel-containing wastewater from electroless Nickel plating was the DS. The diluted DS could be disposed to a wastewater treatment plant. No DS regeneration process is necessary in this case.

More recently, Forward Water Technologies demonstrated industrial-scale piloting of 15 kLD wastewater treatment demonstration site in Canada (see Fig.12). In this process a thermolytic forward osmosis draw solution based on Ammonium Carbamate receipe is employed and distilled drinking water can be obtained from produced water with around $70 \%$ waste reduction 
using an Aquaporin hollow fiber forward osmosis membrane technology developed by the with almost negligible RSF thereby eliminating the brine scrubbing process [110].

\subsection{Organics removal in FO process}

With regard to the organic matter, the growth of review and technical papers before 2007 remained almost constant, after which the number of papers was increased totaling 240 in 2019 (Fig. 4 (C) (SI). Interestingly, the interest in this area was low between 2008 and 2010 accounting for only 63 out of 240 papers. It was noticed that there were interesting growth spikes from 2015 to 2019. This is because organic compounds can cause environmental pollution and health risks for animals and humans. Thus, governments around the world encouraged academic and industrial researchers to find ways to control pollution and minimize contaminants in water [111]. Membrane separation technologies such as LbL membranes is one of the best methods to remove different pollutants from wastewater, but the cost is high. It should be noted that the FO stand-alone process is applicable to treat wastewater to obtain either concentrated wastewater or diluted wastewater. Using the FO process for the removal of organic matter is effective and can yield energy sustainability, an optimized and inexpensive process [112]. An example is a cellulose triacetate-based FO membrane was operated in FO system to remove organic matters (sodium alginate and xanthan gum) in synthetic wastewater depicts that from wastewater treatment plant (WWTP) [113]. The results revealed that the organic matters were effectively separated by the FO membrane reaching more than $81 \%$. This rejection percentage was also increased upon the formation of a fouling layer on the membrane. However, this fouling layer showed loose structure and therefore, some of these organic components were transferred to the $\mathrm{NaCl}$ as a draw solution due to RSF. In parallel, the same membrane was also used to reject organic contaminants such as COD, ammonia nitrogen, total nitrogen, total phosphorus from sewage wastewater [114]. Firstly, the membrane was capable 
of concentrating sewage by $1 / 10$ of its initial volume. The membrane achieved a high rejection rate of about $96.5 \%, 93.3 \%, 89.4 \%$ and $95.4 \%$ for ammonia nitrogen, total nitrogen, total phosphorus respectively. In contrast, the membrane suffered from organic fouling when the water permeation increased due to the high concentration of the draw solution during the FO process. A great water recovery was achievable reaching $90 \%$ and $96 \%$ after physical and chemical cleaning of the fouled membrane.

Overall, the FO system is a potential process for the rejection of different pollutants and the recovery of nutrients from various types of wastewater. Positive findings in an earlier study [115] confirmed that concentrated sewage could replace the anaerobic digestion feed providing good quality effluent. However, some problems need to be overcome to make the FO process feasible for this area. Consequently, this trend in wastewater treatment (especially organic materials) could be expected to continue in the next years and hence fouling resistance membranes can be of great interest to researchers in the future.

\subsection{FO process operation modes}

When used for water treatment or for wastewater volume reduction, FO can be operated in different modes. In applications in which high quality product water is not required, FO can be operated in an osmotic dilution mode, where water drawn from wastewater through the membrane dilutes the DS. The two end products are the diluted DS, which can be valorised, and the concentrated wastewater. The osmotic dilution mode is illustrated in Fig. 13 (a) and (c). In applications where high quality product water is required, FO can be coupled with a process such as RO to systematically re-concentrate the DS and produce a high quality permeate. In the latter case, FO acts as a high-level pre-treatment step before the desalination process; this pre-treatment mode is illustrated in Fig. 12 (b) and (d) [109, 116]. Thus, FO 
process can be operated as a standalone process (osmotic dilution mode), or combined with a draw solution recovery process such as RO or membrane distillation (dual barrier) [117].

\subsubsection{Osmotic dilution}

Finding industrial applications which do not necessitate an external supply of draw solution or a re-concentration process for the diluted draw solution could be one effective solution to pushing forward the real-world commercialization of FO. In those application fields, simplification of the FO-based system can be achieved by eliminating the draw solution recovery process, and therefore several economical and technical problems on draw solution would be easily solved. From this point of view, any potential application of FO should meet the following conditions: (1) more than two streams having substantially different osmotic pressures are locally available, (2) a lower saline solution needs to be concentrated, and (3) a liquid having higher osmotic potential does not need to be recovered after its dilution.

\subsubsection{Fertilizer drawn forward osmosis (FDFO)}

The concept of fertiliser drawn FO (FDFO) has been gaining increased attention as a promising application in water reclamation and reuse $[118,119]$. As shown in the Fig 14 in FDFO processs, the FO membrane unit was employed. One side of the FO membrane was facing feed solution and other side towards the drw solution which is fertilizer draw solution in this application. After water extraction diluted DS can used for irrigation without further dilution. A very high concentration difference between DS (single fertilizer or blended fertilizer) and feed water makes water permeation from feed to the draw side of the FO membrane. In the preliminary FDFO tests promising results were obtained that suggested 11-29 L of fresh water from seawater extraction potential of this process from $1 \mathrm{~kg}$ commercial fertilizer with only energy consumption counts to run feed and draw solution pump as FO membrane works on 
osmotic pressure principle. The only energy used in this process is for running two pumps which does not exert any hydraulic pressure. Hence, FDFO desalination has potential to produce irrigation water with comparatively less energy consumption than the current desalination technologies. Moreover, FDFO can be easily powered by renewable energy sources and therefore suitable for inland and remote applications [120].The technology shows its potential for the irrigation in coastal areas with water scarcity [121].

However, as stand-alone FDFO could not be able to produce water quality in terms of TDS and nutrient $(\mathrm{N} / \mathrm{P} / \mathrm{K})$ concentration for direct dertigation the integration of NF with FDFO desalination as either pre-treatment or post-treatment was proposed [122]. Pressure-assisted forward osmosis (PAFO) has been recently introduced in a recent FDFO study. PAFO could potentially eliminate the need for further post-treatment. In fact, the additional water flux generates in the process can enhance the final fertiliser DS dilution beyond osmotic equilibrium making the final product water suitable for direct fertigation [119, 123].

\subsubsection{Osmotic concentration-Regeneration of DS and energy consumption}

There are still challenges with newly developed, responsive draw solutions. For example, a $\mathrm{CO}_{2}$-responsive draw solution contains hydrophobic amines in the structure can react with $\mathrm{CO}_{2}$ and transform to the hydrophilic product. This causes an increase in the osmotic pressure of the draw solution [73]. However, these products are not compatible with the FO membrane and the selective layer might be swollen and degraded by amines. Thus, these membranes prone to irreversible fouling which needs periodic chemical cleaning. This caused an increase in energy expenditure and operating costs. Another concern is the regeneration of the draw solution which increases also the energy consumption and operation prices. The recovery system for the draw solution is related to the overall FO system which is crucial for the effective 
implementation of FO. The recovery rate efficiency when treating actual contaminated water is also important for the feasibility of the full-scale FO system. The regeneration of the draw solution has been a noticeable research activity from 2013 as the number of reviews and technical papers doubled reaching 68 documents, after which the publications became higher of about 235 documents in 2019 (Fig. S4 (B) SI). Interestingly, the number of published records remained almost stable during the years 2015, 2016, 2017. Earlier efforts to regenerate the draw solution using membrane separation processes could produce great water recovery rate [124], however, these potential systems yield to further energy consumption and cost increment of the operations. Other researches on industrial-sized FO desalinization processes have been conducted at low recovery rates and no information on the optimization of the hybrid system, recovery stage of the draw solution and investigating the change in nature and composition of the draw solution over time. A significant need for further experiments on pilot-scale studies should be carried out to get an insight on the great recovery performance of the hybrid system, the optimal process conditions of the hybrid system, the quality of both the regenerated solution and the pure water and estimating the energy consumption of the recovery system while the need for effective regeneration system for the draw solution increases, energy expenditure and its cost are also raising dramatically. The development of the energy-efficient hybrid system has become an urgent problem.

When the flow rate of the draw solution was reduced from 100 to $10 \mathrm{~mL} \mathrm{~min}^{-1}$, the energy consumption was lowered from 1.86 to $0.02 \mathrm{~kW} \mathrm{~h} \mathrm{~m}^{-3}$ [125] as the pumps generate higher than $40 \%$ of the overall energy prices [126]. It must be however mentioned that this flow rate of the draw solution can increase the energy demand in the FO process and has not been well studied in the literature for different FO applications. Although chemical recovery is a potential strategy, adding chemicals into the draw solution is a costly way and requires further disposal of these chemicals. Therefore, minimizing the energy is essential for reducing the operation 
cost and highlighting the environmental impact of greenhouse gases emissions from using fossil fuels as power source for operating the industrial plants. It is evident that most of the research documents issued in the recent 10 years and this research trend is expected to grow in the future.

\section{Challenges and future directions}

Among the abovementioned research areas, research activities on FO are focused on wastewater reclamation, draw solutions, fouling, membrane fabrication and modification. It is recognized that the specific research areas have some technical limitations related to wastewater treatment, draw solution, cost and energy-efficient regeneration process, and membrane manufacturing need to be overcome.

FO process showed a highly promising platform in treating various effluents such as wastewater and salty water, while generating product water having different qualities like diluted salty water or clean water for non-potable reuse purposes. However, there are many practical barriers that impede the implementation of the FO system for treating wastewater in industrial scale. Researches on wastewater reclamation were performed using synthetic wastewater with low concentrations and did not depict the actual wastewater in industrial plants. FO system can be a potential pre-concentration stage of an AnMBR and direct sewage concentration, but further improvement in the design of the system and optimization of the operation parameters are essential. To advance the FO operation, additional tests are required while real wastewater should be processed in the FO system under operating conditions reflecting the industrial plant. As FO alone cannot desalinate high salinity water (brackish water/seawater), it can be coupled with another pressure-driven membrane as a pre-treatment step. The FO system is an energy-wise approach to dilute the seawater stream using an impaired feed solution with low salt concentration to generate a diluted draw solution as a feed solution 
for the recovery system. Thus, the diluted draw solution includes low salinity and the pressuredriven process can produce highly pure water as a recovery system. Besides, this process minimized the amount of impaired feed solution and fouling on the membrane. FO can be connected to anaerobic treatment to obtain biogas and recover nutrients from wastewater. It is a competitive application and deserves to become an outlook for further explorations.

Additionally, the draw solution must be easily recycled utilizing an energy-saving method to recover potable water. One of the drawbacks of DS regeneration is the high energy consumption of pumping and high overall cost of the process which depends on the type of the used draw solution. However, the breakthrough is essential in the draw solution and regeneration system as these should be studied according to the overall system approach. The thermally responsive polymer is a promising candidate as a draw solution. The osmotic pressure is limited and may not produce the initial osmotic pressure after the regeneration process. Therefore, the functionalization cross-linkers and synthesis procedures need to be optimized. Even though the regeneration of thermally responsive polymers is a simple method, the efficiency of these methods is low due to the poor quality of the product water. Increased attention is directed towards shape memory polymer (SMPs) which were used earlier in many applications such as biomedical devices, deployable space structures, smart dry adhesives and fasteners, and adaptive optical devices [127]. Shape memory polymer (SMPs) are polymer able to memorize its initial shapes temporary even tow shapes are possible. It can be transformed to its original shape under a suitable external stimulus like light or heat or magnetic field or electrical source, or moisture $[127,128]$. Importantly, these shape memory polymers can generate recovery stress of more than 1.8 Mpa. By incorporating a reversible bidirectional shape memory polymer (rbSMP) into the thermally responsive hydrogel, it may be a promising 
strategy to enhance the dewatering efficiency. It would be interesting to explore their efficiency as draw solutions for realizing the FO desalination application.

To evaluate the feasibility of the recovery system to finish the water treatment cycle, it was recommended to use a full-scale membrane module. Few studies have been reported on the assessment of large-scale modules for the recovery system. There are still some limitations that encounter the standard operation protocol for these modules, fouling, and high cost. For example, when testing these modules fouling usually occurred, and hence, the membranes required effective cleaning. However, there is no guarantee that the membrane would restore its initial efficiency. Replacing the membrane module frequently would require more money in comparison with the coupon membrane, which they can be tested and replaced due to fouling achieving lower cost.

Potential integrated hybrid methods can be employed to optimize the efficiency of the FO system. It is assumed that using natural energy sources (i.e., wind or solar thermal power) or waste heat from industry or geothermal energy or biomass power might be a potential option to minimize the energy consumption and operating cost imparted from the second recovery system. To best of our knowledge, when enhancing the energy consumption using membranes with high permeability, the quality of product water should remain high with minimum salinity and boron components.

In contrast, the development of reliable models to predict the energy expenditure is still of a great challenge to the researchers. It is necessary to optimize the energy consumption of the well-established FO stand-alone system or hybrid system to transform the process into a feasible industrial application for water treatment. Furthermore, a simple semi-empirical model for estimating water permeability and solute permeability which depicts the transfer behavior in the FO membrane during the experiment, is an open venue for future research. A promising 
way for decreasing the energy expenditure is the manufacturing of membranes using low energy materials and advanced nanomaterials to improve the water flux and salt rejection.

In terms of membrane development, some drawbacks must be overcome to achieve the successful installation of FO in the industry. Thus, the development of the membrane should contribute considerably to the efficiency of the FO system. For example, the available FO membranes in the industry are expensive and new ways of reducing the price are needed. If the membrane achieves great water permeation and antifouling property, these features may contribute to the low price of the membrane. This can be fulfilled by the physical and chemical modification approaches such as layer by layer. Although the hydrophilicity and wetting properties were enhanced resulting in high water flux, applying a number of layers on FO membranes induced the hydraulic resistance. Despite the promising results on this technique, the practicality is limited for bench-scale and more experiments are necessary to determine the performance of LbL membrane in large scale operations for different FO applications. Also, novel antifouling materials and functional materials can be used to produce membranes with dual functionalities [129]. To achieve a high recovery rate and water flux in short operating time, the membrane area should be large; however, most of the earlier works used a membrane coupon area less than $20 \mathrm{~cm}^{2}$ for the cross-flow process [130].

The severity of fouling associated with RSF poses great concern and hence innovative mitigation strategies with minimum cost must be developed. In-situ real-time assessment protocols of membrane fouling using various applications is an urgent need to understand the mechanism. One possible way to delay the interaction between foulants and membrane surface is a surface modification and functionalization by an additional enthalpic barrier, electrostatic repulsion, and steric hindrance. More investigations are needed to deal with the limitations like 
the trade-off effect among permeability and selectivity. Looking for potential nanomaterials in the sense that they offer perfectly selective conduits for water with great water permeation and rejection rate. A new generation of graphene membranes and membranes impregnated synthetic water channels may provide ultrahigh water permeability and acceptable salt rejection [131]. Further modifications in membrane design are important for exploring advanced applications by aquaporin embedded TFC FO membranes. Outer surface active layer hollow FO membranes will be ideal to improve the packing density and fouling mitigation of different feed water solutions. Currently, a pilot project on wastewater treatment from the semiconductor industry has been established in Singapore. Aquaporin based biomimetic FO membranes were used for wastewater treatment. Lastly, according to a closed-loop hybrid FORO/MF/UF/NF/MD system, the most crucial elements to energy expenditure and sustainability are the regeneration of the draw solution by the hybrid system and the performance of FO membrane. 


\section{Conclusions}

Over the last decade, FO technology has been searched extensively due to its advantages over conventional water treatment approaches. The most important areas discussed in these publications were draw solution, membrane fabrication and modification, hybrid system, mathematical modeling, energy consumption, and techno-economic analyses. According to Science Direct database, the total number of reviews and research papers on FO membranes and processes has been growing annually approaching around 5232 publications in the year 2020. The vast majority of these research documents around 2413 covered fouling issue for different FO applications. So far, many publications were also published on various types of draw solutions approaching around 1679 in the last decade. Most of the efforts made on evaluating the performance of draw solutions were based on the inorganic and organic based draw solution, with around $20 \%$ for each one. Within the context of this review, recent advances on membrane fabrication and modification showed increasing trend of around 1063 articles in the last decade. A rapid increase in the publications was noticeable from 2013 to 2019 approaching 235 articles. By performing more experiments, the up scaling of pilot scale systems will be the next stage towards commercialization of FO membrane modules for potential industrial applications.

Wastewater treatment using FO process was acknowledged as one of the most important applications. The interest in employing FO process for the removal of different organic matters has been increased remarkably in recent years. Since 2007, there is an annual increment in the number of publications of around 240 articles. Along with the technical viability, energetic and cost benefits of the FO system should be critically assessed for all applications before commercialization. As unveiled in this review, recycling the draw solution and energy consumption are the most important potential research areas that have shown growth in the number of publications over the last eight years. To further promote FO process in industry, 
optimizing of the energy consumption and establishing an effective recovery system are essential. Finally, FO stand great promises especially with its potential to concentrate complex wastewater, reduce energy demand and cost. Thus, the interest in this process has been increasing these years and expected to be continued in the future.

\section{Acknowledgments}

The authors acknowledge the support of Qatar National Research Fund, Qatar Foundation for Education, Science and Community Development on providing the $\mathrm{PhD}$ scholarship to $\mathrm{W}$. Suwaileh and ARC Industrial Transformation Research Hub (IH170100009). The authors from

Swansea University are grateful to the Royal Society for the financial support through Royal Society International Collaboration Award (IC160133) in the realization of this work. 


\section{List of captions}

Figure.1: (a, b) Showing the total number and the percentage of FO publications documented in Science Direct on FO process from 1999 up to date.

Figure.2: (a, b) Illustrating the total quantity and the percentage of publications documented in Science Direct on different membrane modules per year.

Figure. 3:Forward osmosis major industrial players.

Figure. 4: FO membrane development.

Figure. 5: Draw solute evolution.

Figure. 6: Proposed SPS FO water purification process (Reproduced from Stone, Rae, Stewart and Wilson [73]).

Figure. 7: Forward osmosis industrial applications.

Figure. 8: Forward osmosis industrial applications a) Simplified sketch for FO as a pre-treatmet to RO seawater desalination b) The PAEW Water Site at Al Khaluf.

Figure. 9: Energy efficient desalination (TreviSystems 2020).

Figure. 10: Multi-stage flash (MSF)-FO desalination processes (Darwish, Hassan et al. 2016).

Figure. 11: Coal-fired power-plant wastewater Changxing power plant in China (Membrane brine concentrator (ZLD)) (OasysWater 2017).

Figure. 12: Industrial scale pilot plant demonstrating low energy ZLD using thermolytic DS from FO Technologies.

Figure. 13: FO process operation modes: (a);(c) FO process operated in pre-treatment mode, (b); (d) FO process operated in osmotic dilution mode (Roy, Rahni et al. 2016, Gwak, Kim et al. 2018).

Figure. 14: Fertilizer drawn forward osmosis process (Phuntsho, Shon et al. 2012).

Table 1: The number of publications in each FO topic in the last two decades. FO-forward osmosis process, DS-draw solution, F\&M-fabrication and modification, RS-recovery system, M\&S- modeling and simulation, and EC-energy consumption. 
Table 2: General DS characteristics affecting FO process performance and their impact on the process performance (Reproduced from Chekli, Phuntsho, Shon, Vigneswaran, Kandasamy and Chanan [132]). 
Graphical abstract

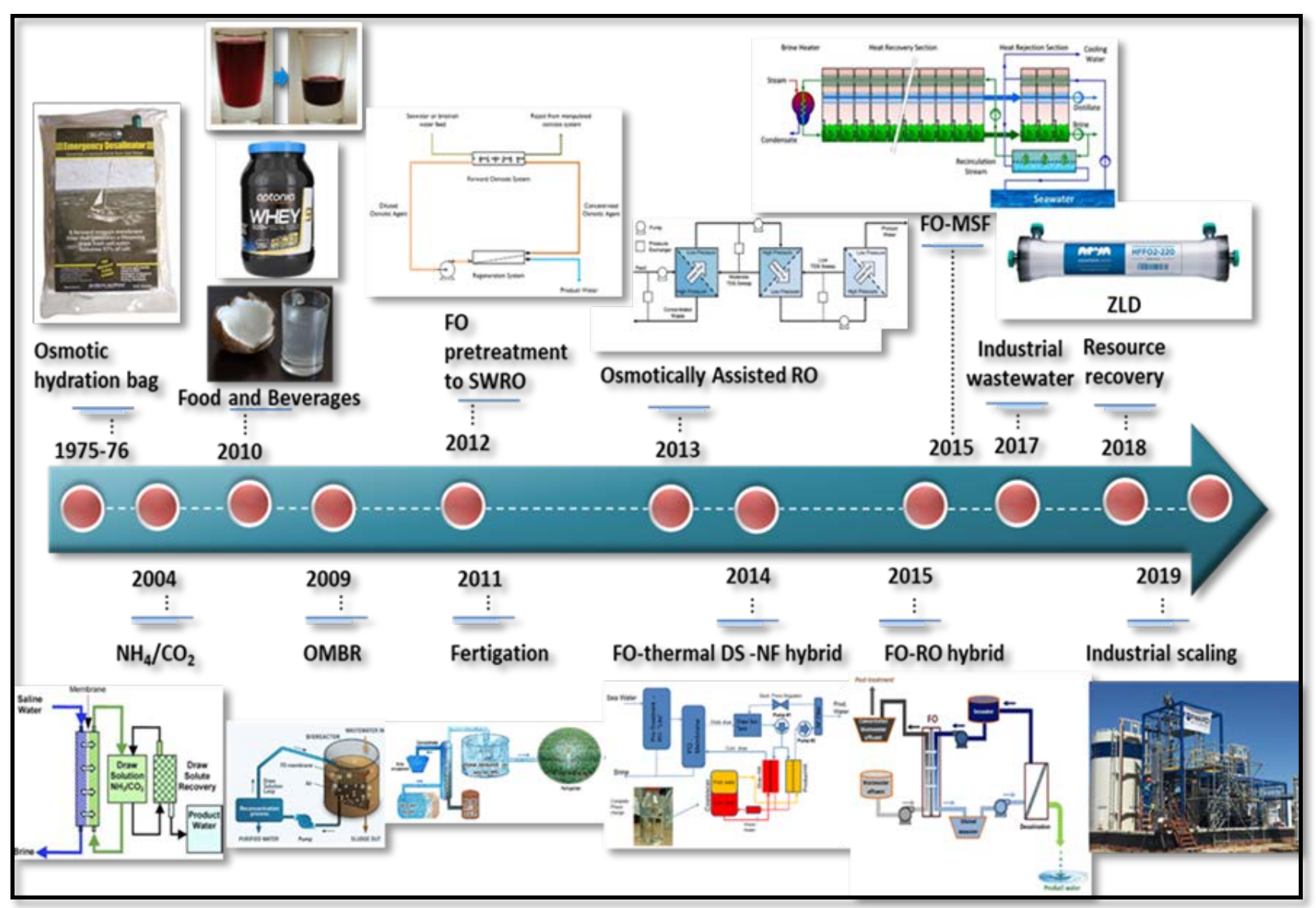


Figure.1
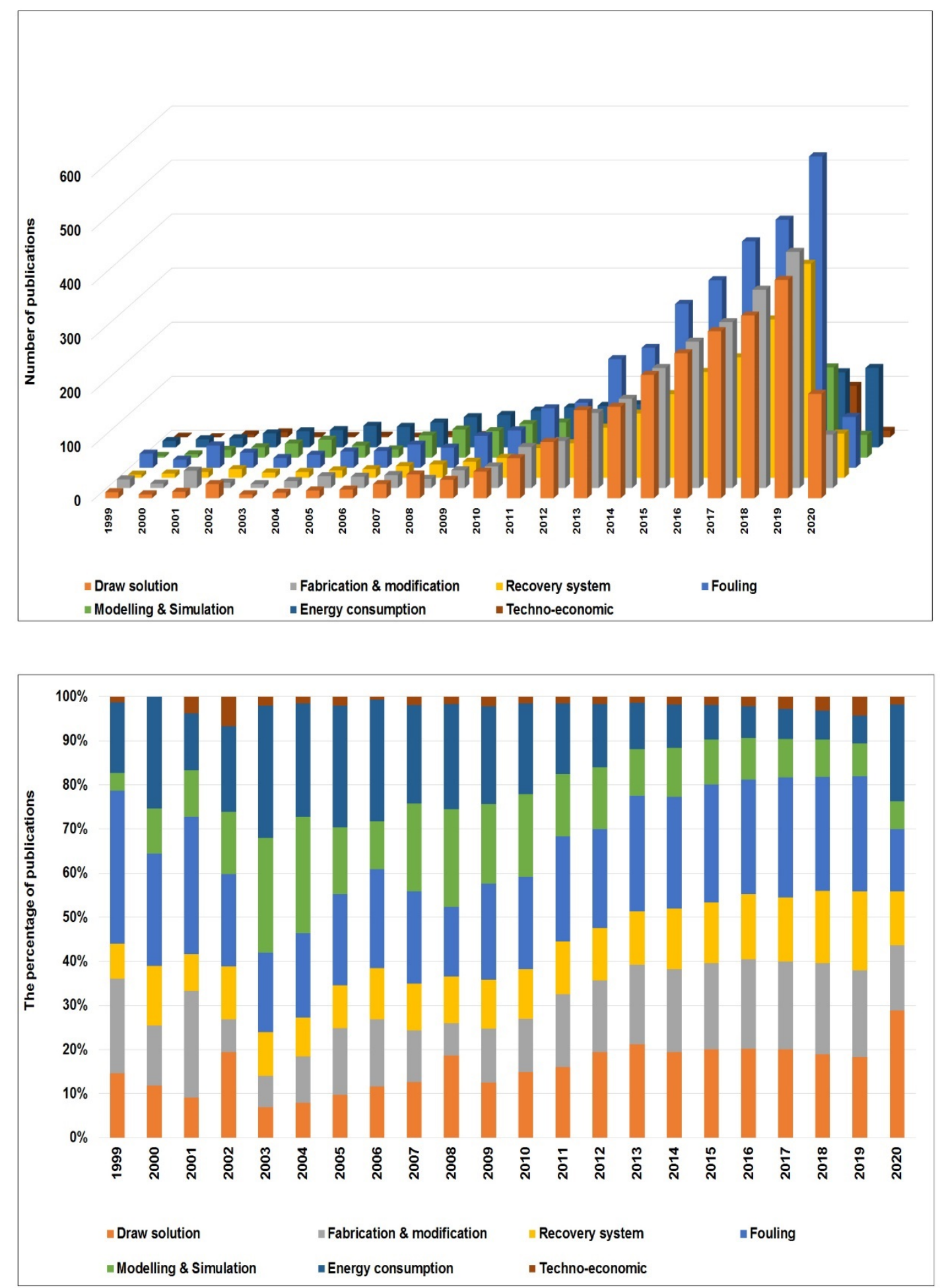
Figure.2

A

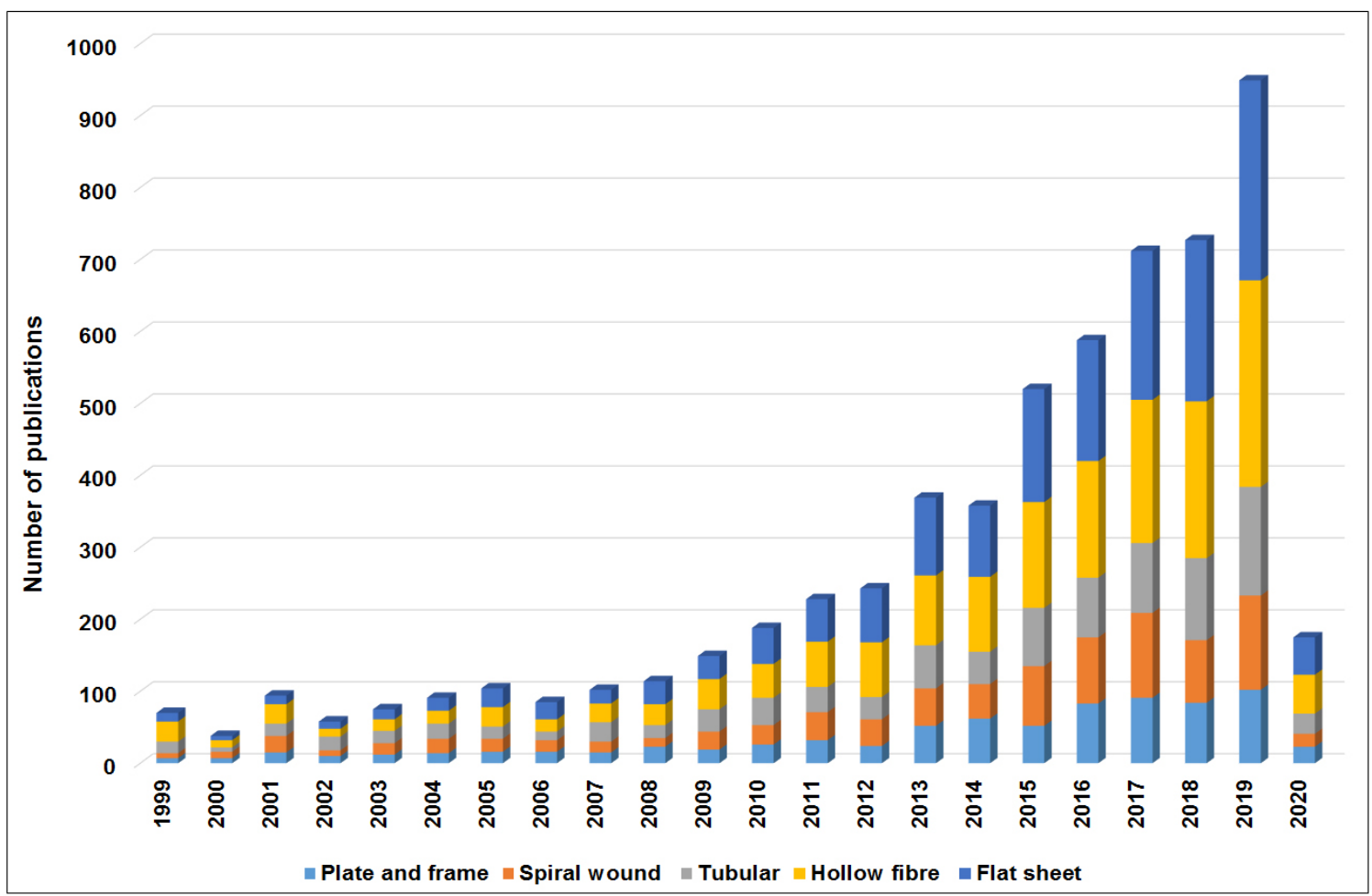

B

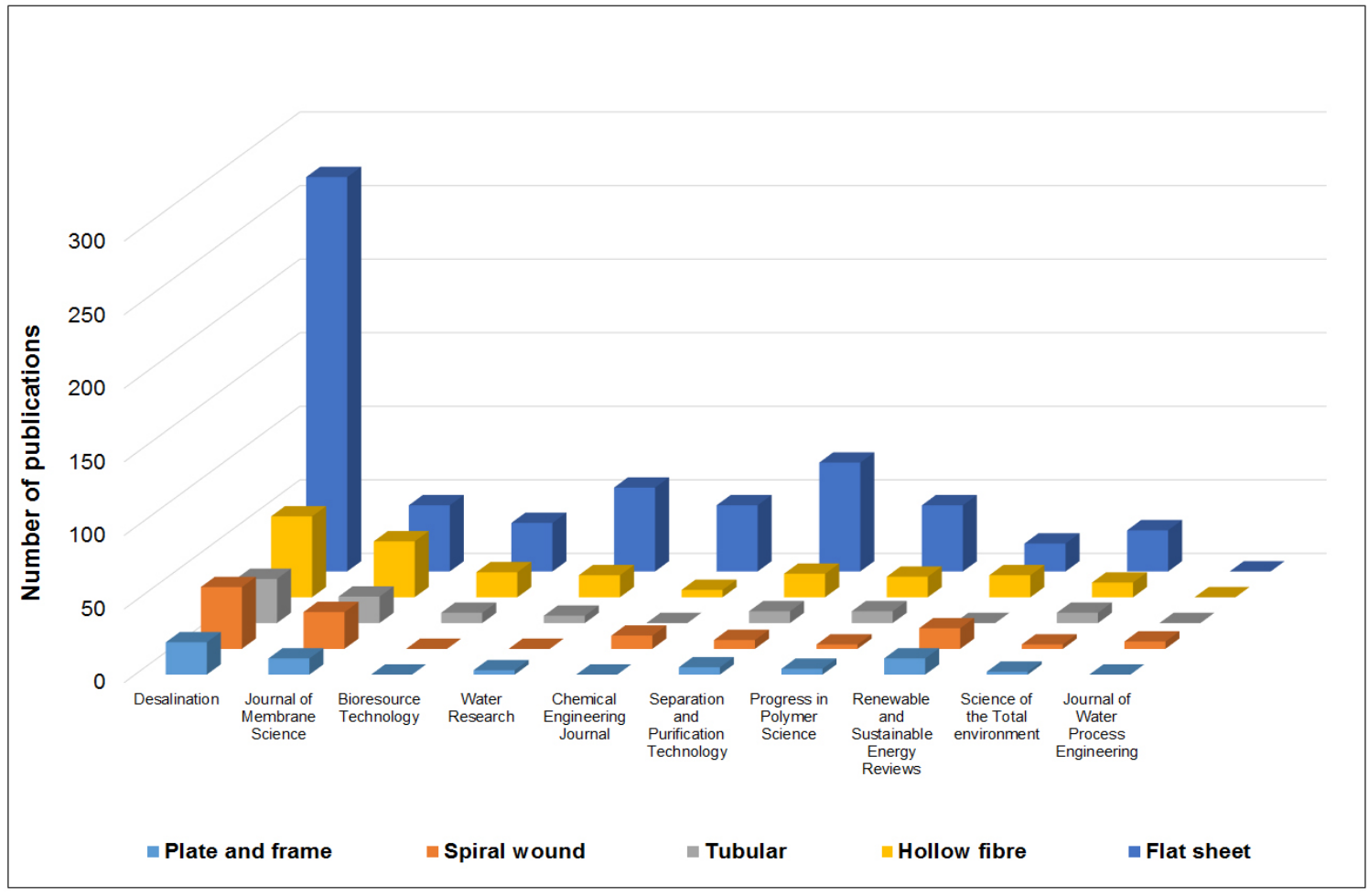


Figure. 3

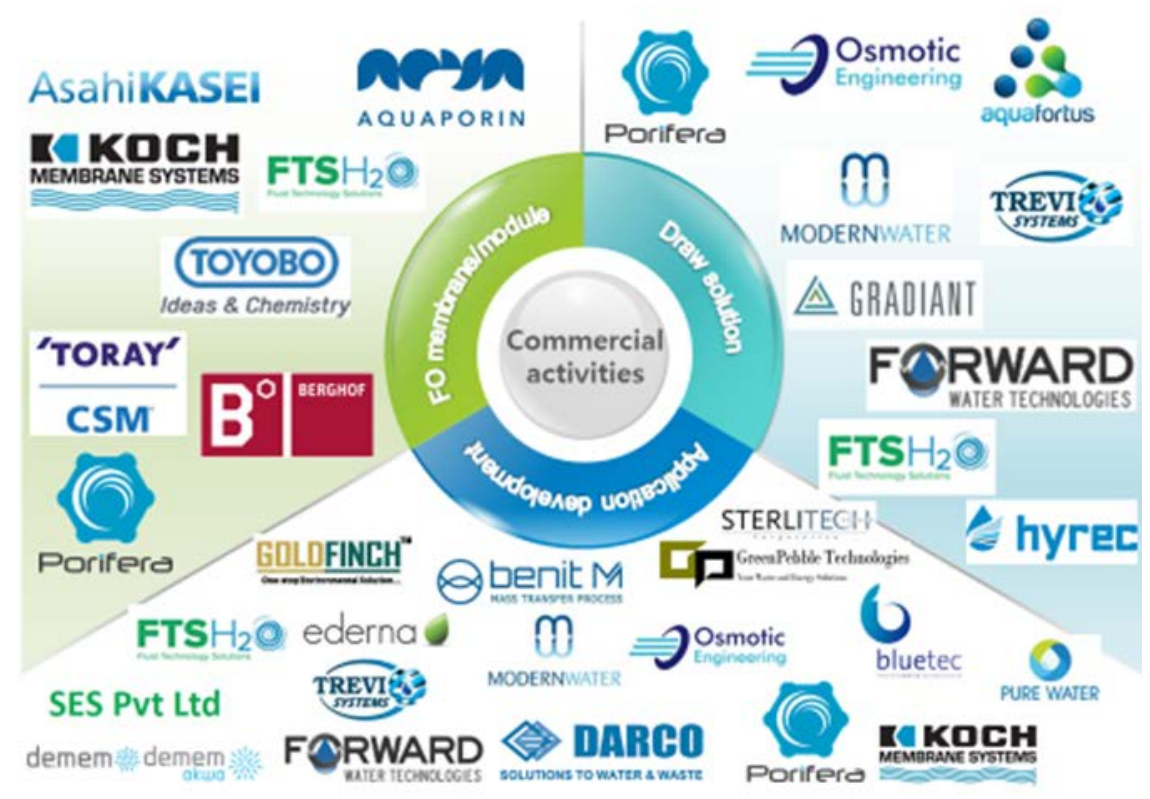


Figure. 4

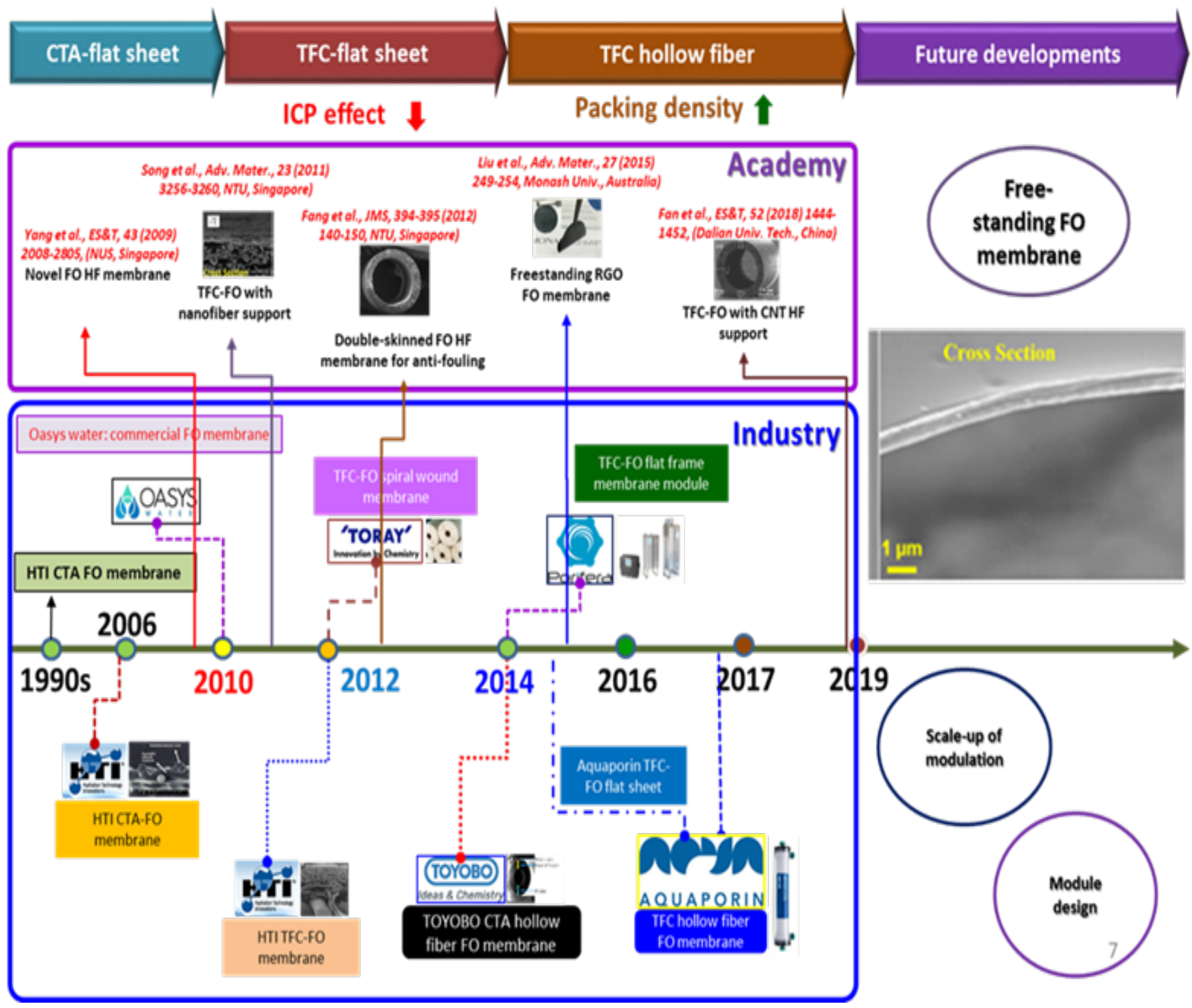


Figure. 5

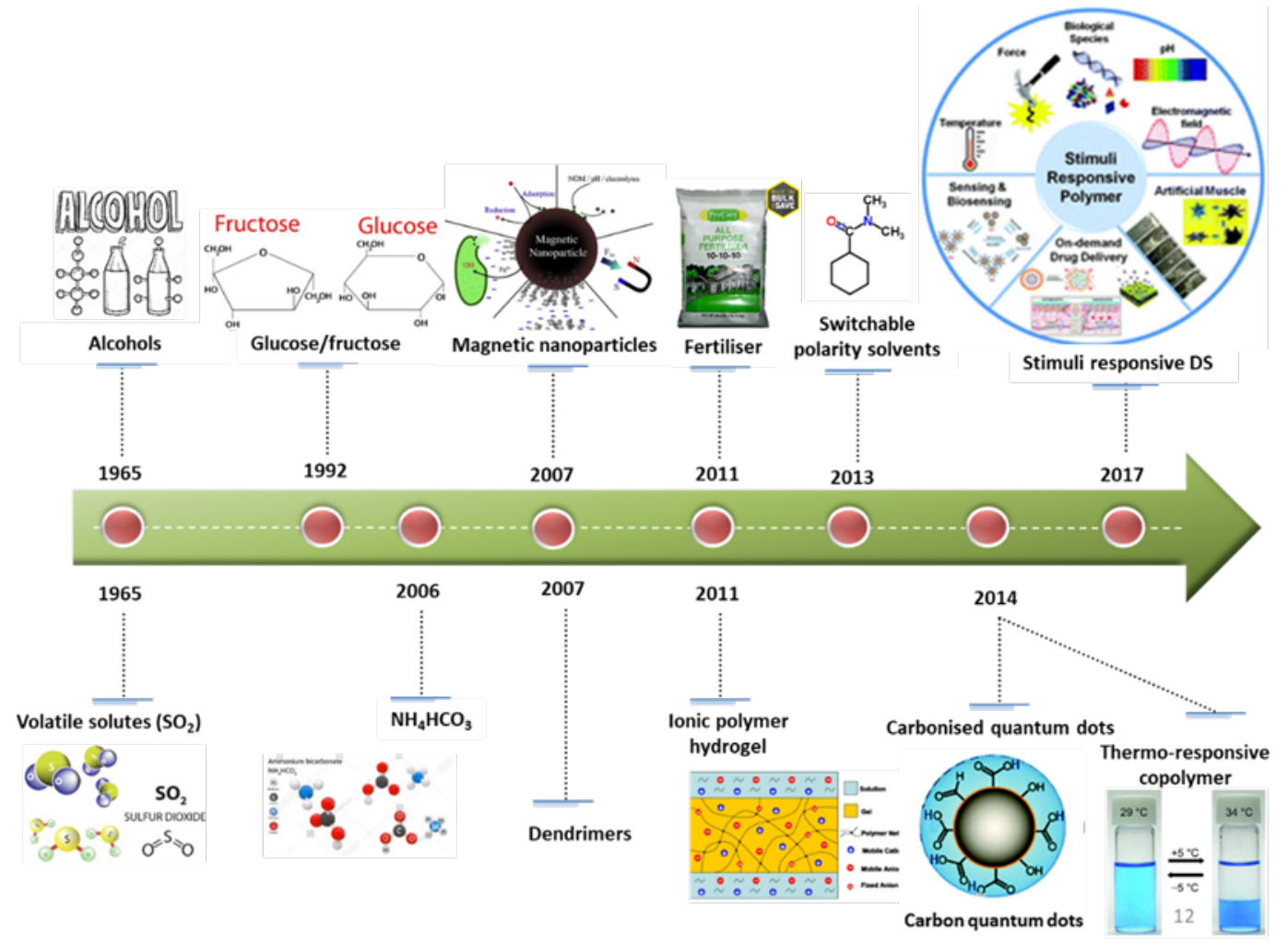

Figure. 6

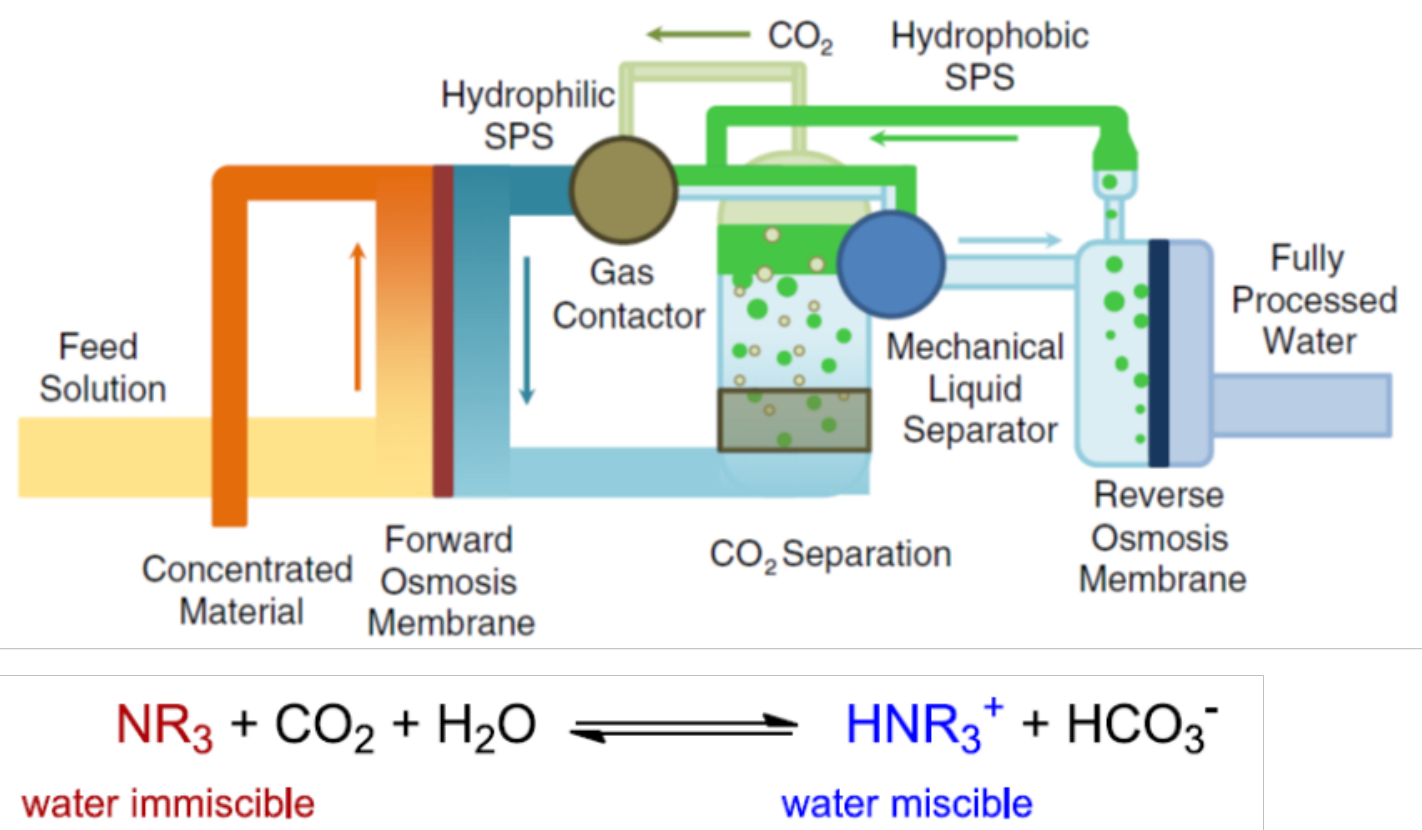


Figure. 7

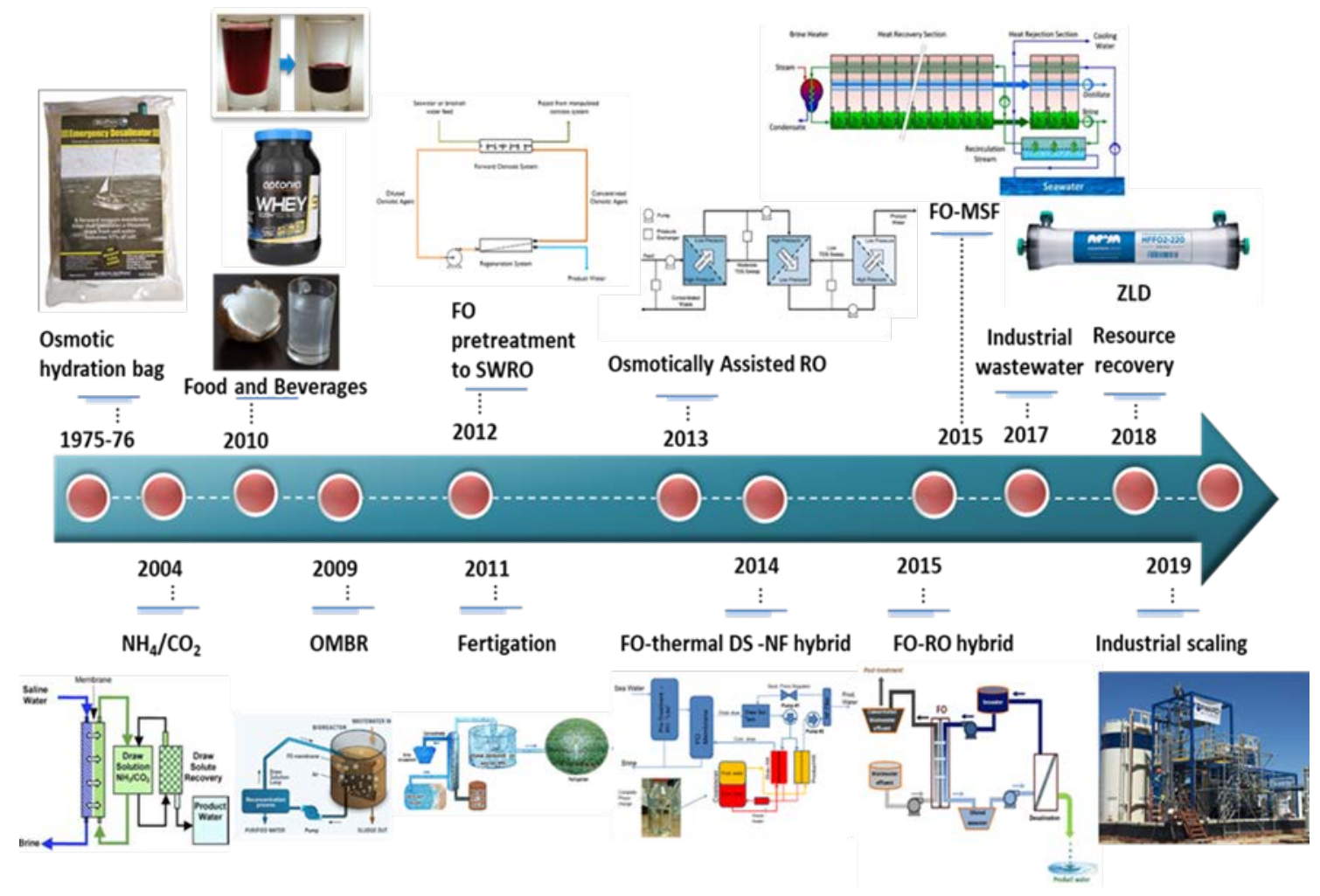

Figure. 8

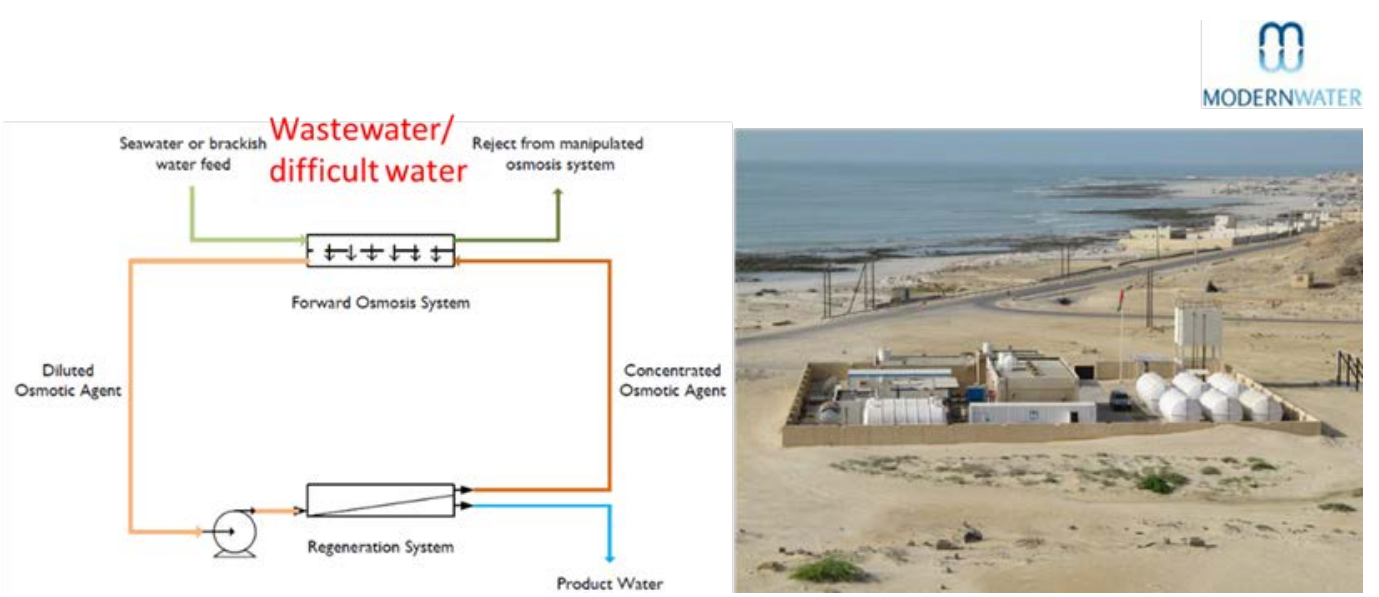


Figure. 9

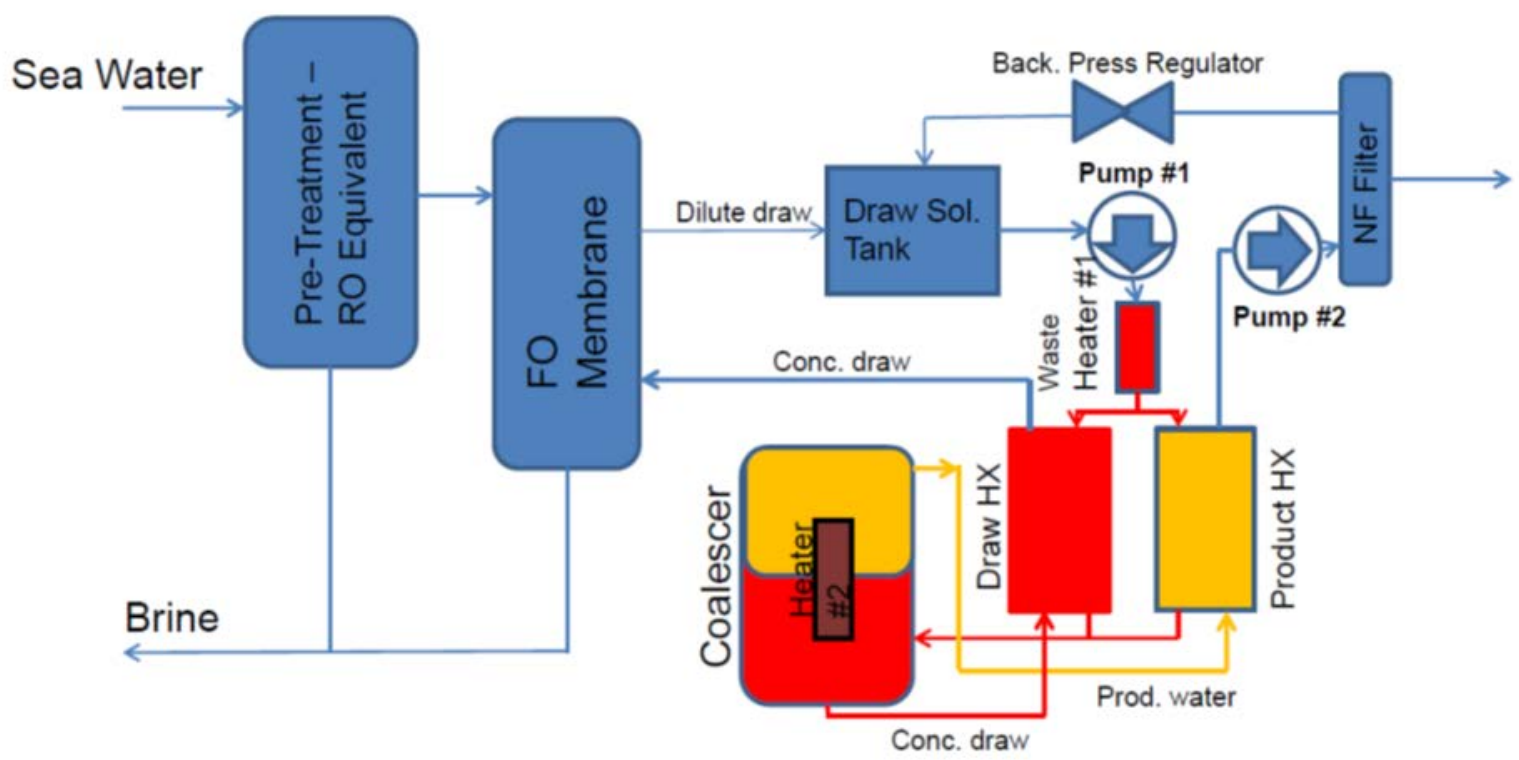


Figure. 10

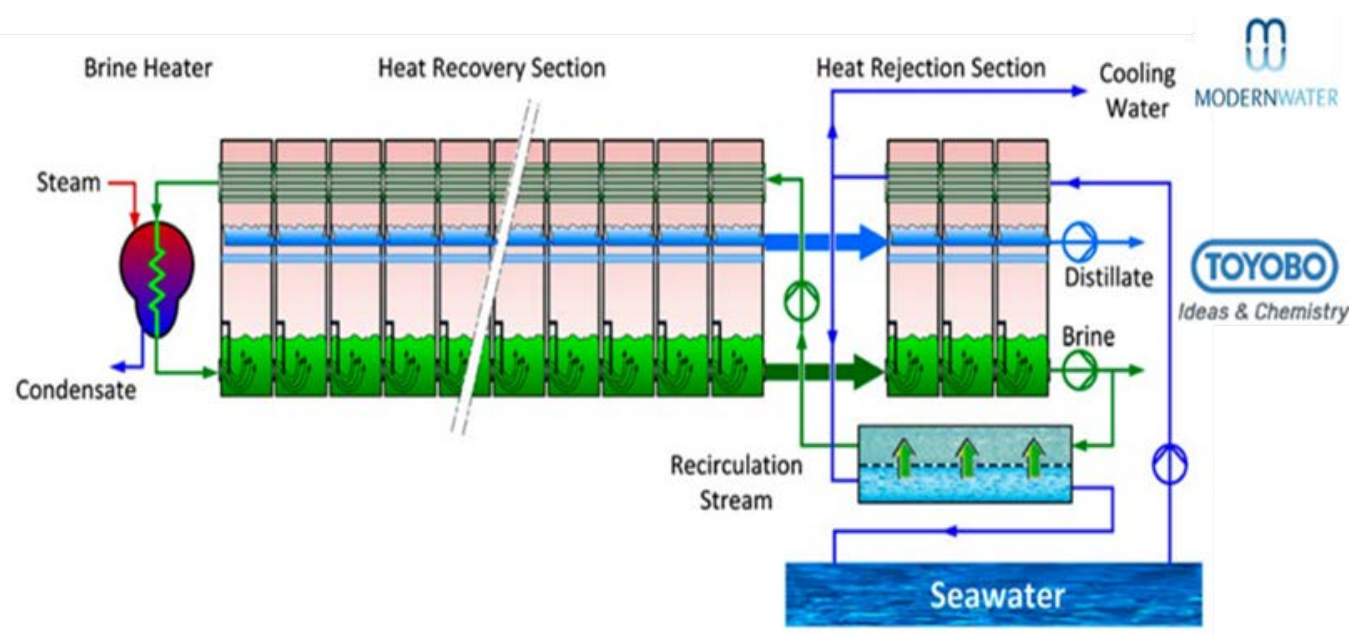

Figure. 11
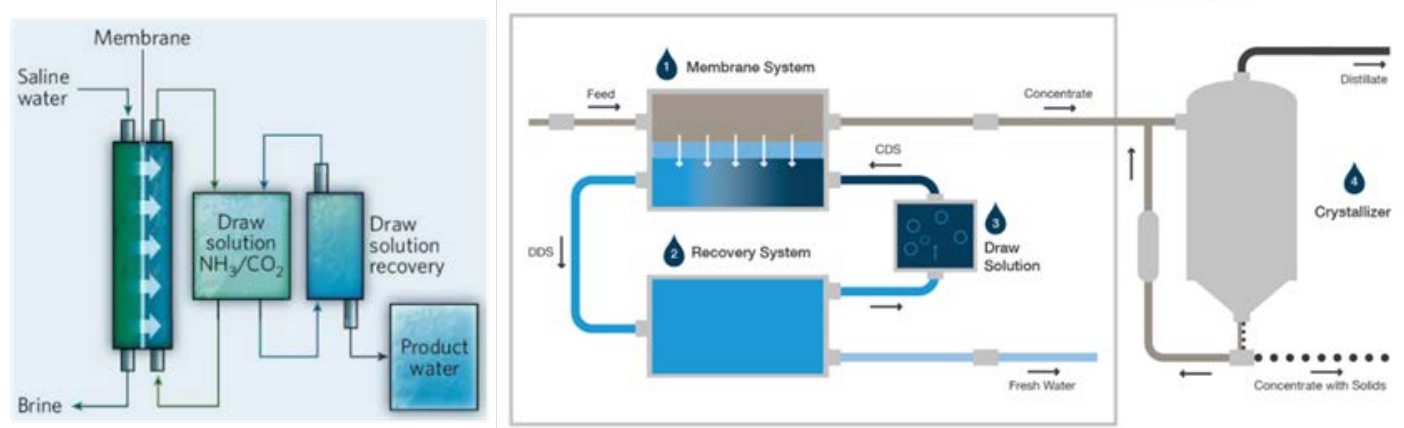
Figure. 12

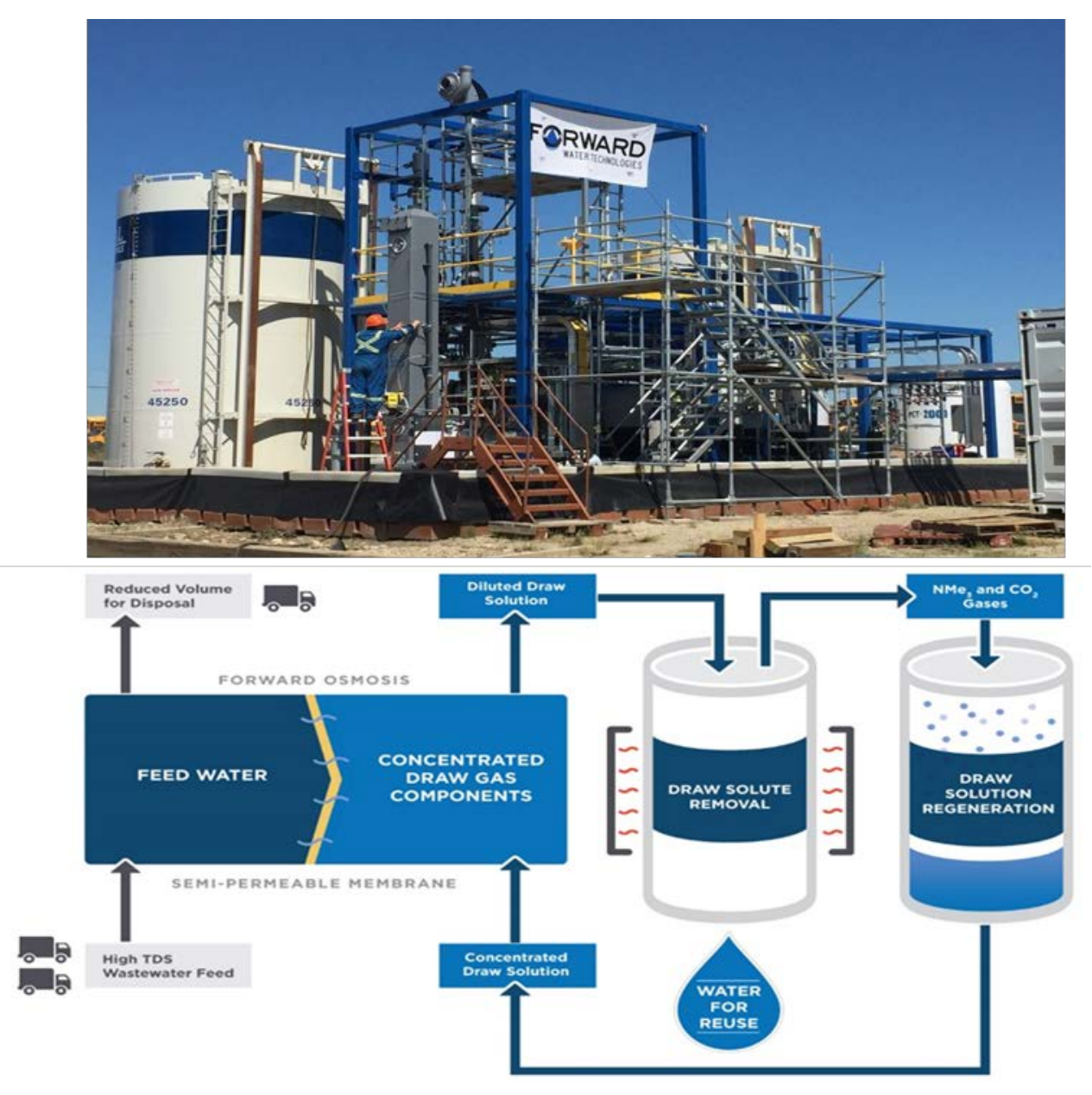


Figure. 13

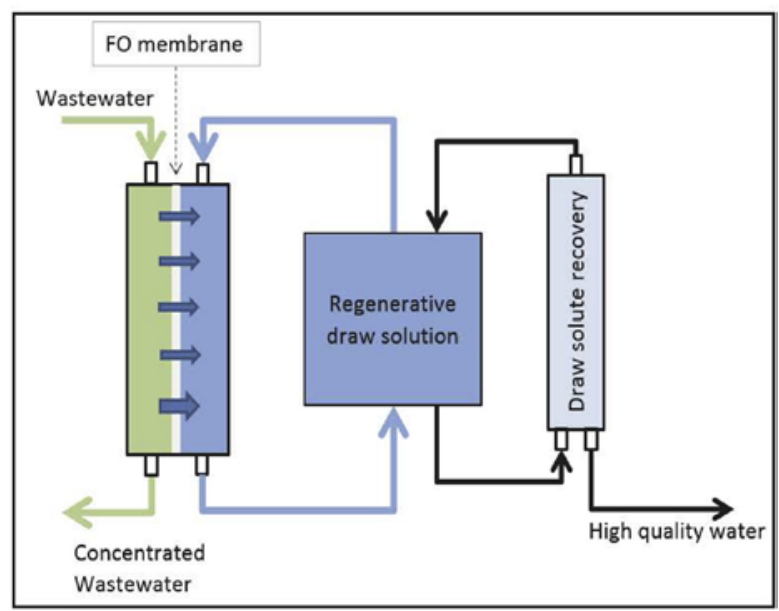

(a)

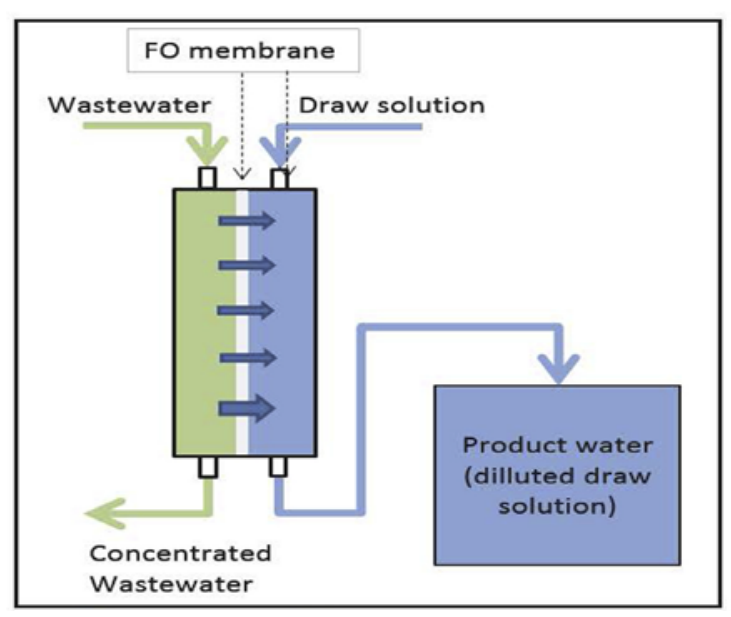

(b)

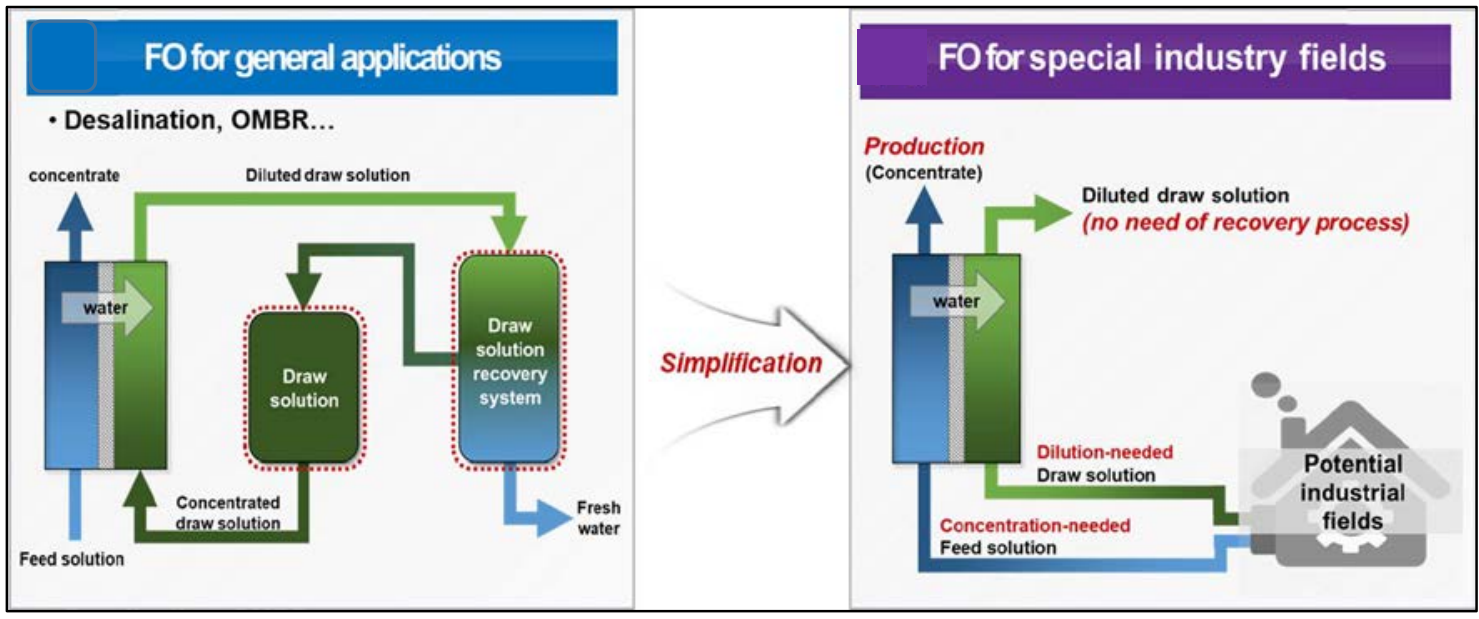

(c)

(d) 
Figure. 14

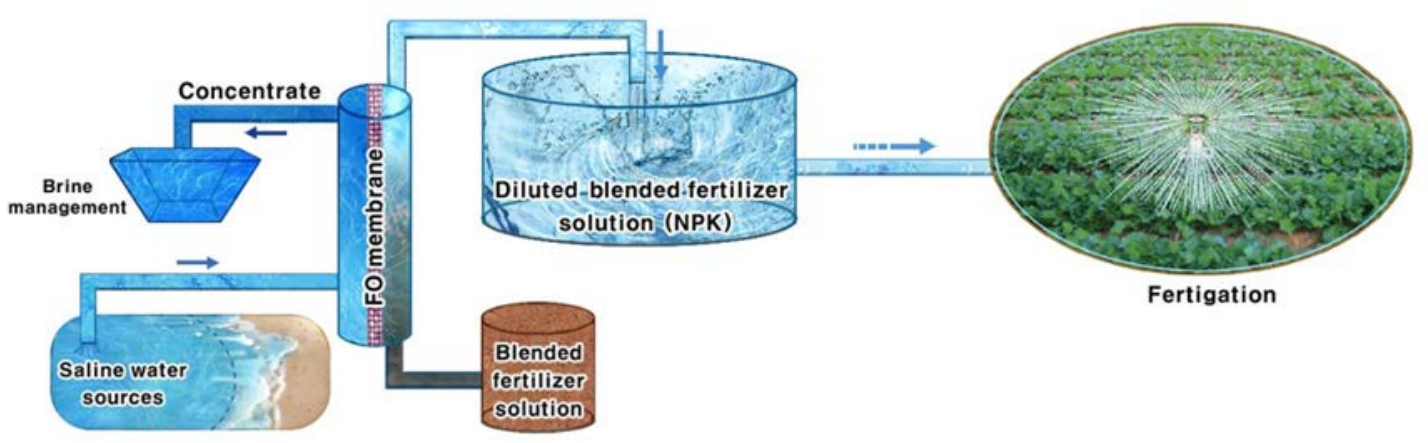


Table 1

\begin{tabular}{|c|c|c|c|c|c|c|c|}
\hline Year & $\begin{array}{c}\text { Draw } \\
\text { solution }\end{array}$ & $\begin{array}{c}\text { Fabrication } \\
\& \\
\text { Modification } \\
\end{array}$ & $\begin{array}{l}\text { Recoery } \\
\text { system }\end{array}$ & Fouling & $\begin{array}{c}\text { Modeling } \\
\text { \& } \\
\text { Simulation }\end{array}$ & $\begin{array}{c}\text { Energy } \\
\text { consumption }\end{array}$ & $\begin{array}{l}\text { Techno- } \\
\text { economic }\end{array}$ \\
\hline 1999 & 11 & 16 & 6 & 26 & 3 & 12 & 1 \\
\hline 2000 & 7 & 8 & 8 & 15 & 6 & 15 & 0 \\
\hline 2001 & 12 & 32 & 11 & 41 & 14 & 17 & 5 \\
\hline 2002 & 26 & 10 & 16 & 28 & 19 & 26 & 9 \\
\hline 2003 & 7 & 7 & 10 & 18 & 26 & 30 & 2 \\
\hline 2004 & 10 & 13 & 11 & 24 & 33 & 32 & 2 \\
\hline 2005 & 14 & 22 & 14 & 30 & 22 & 40 & 3 \\
\hline 2006 & 16 & 21 & 16 & 31 & 15 & 38 & 1 \\
\hline 2007 & 26 & 24 & 22 & 43 & 41 & 46 & 4 \\
\hline 2008 & 44 & 17 & 25 & 37 & 52 & 56 & 4 \\
\hline 2009 & 34 & 33 & 30 & 59 & 49 & 60 & 6 \\
\hline 2010 & 49 & 40 & 37 & 69 & 62 & 68 & 5 \\
\hline 2011 & 74 & 76 & 55 & 110 & 65 & 74 & 7 \\
\hline 2012 & 104 & 87 & 64 & 120 & 75 & 77 & 9 \\
\hline 2013 & 163 & 139 & 93 & 201 & 82 & 80 & 11 \\
\hline 2014 & 169 & 165 & 119 & 222 & 96 & 86 & 16 \\
\hline 2015 & 228 & 222 & 155 & 303 & 116 & 89 & 22 \\
\hline 2016 & 268 & 271 & 196 & 347 & 125 & 96 & 29 \\
\hline 2017 & 309 & 307 & 223 & 419 & 134 & 105 & 43 \\
\hline 2018 & 338 & 367 & 293 & 459 & 151 & 117 & 57 \\
\hline 2019 & 404 & 437 & 396 & 576 & 167 & 139 & 95 \\
\hline 2020 & 193 & 99 & 82 & 94 & 42 & 147 & 12 \\
\hline Total & 2506 & 2413 & 1882 & 3272 & 1395 & 1450 & 343 \\
\hline
\end{tabular}


Table 2

\begin{tabular}{|l|l|}
\hline \multicolumn{1}{|c|}{ DS characteristics } & \multicolumn{1}{|c|}{ Impact on FO process performance } \\
\hline Osmotic pressure & $\begin{array}{l}\text { A high DS osmotic pressure and low feed solution osmotic pressure } \\
\text { induce high water fluxes across the membrane }\end{array}$ \\
\hline $\begin{array}{l}\text { Viscosity/ } \\
\text { diffusivity }\end{array}$ & $\begin{array}{l}\text { High solubility induces high osmotic pressure and therefore can achieve } \\
\text { high water flux and high recovery rates }\end{array}$ \\
\hline $\begin{array}{l}\text { A low viscosity combined with high diffusivity leads to high water fluxes } \\
\text { (MW) }\end{array}$ & $\begin{array}{l}\text { Small MW solutes produce higher osmotic pressure than larger MW for } \\
\text { equal mass of DS but induce higher reverse draw solute flux than larger } \\
\text { MW DS }\end{array}$ \\
\hline Concentration & $\begin{array}{l}\text { Water flux increases at higher DS concentration but the increase is non- } \\
\text { linear. At higher DS concentration, dilutive CP drastically increases } \\
\text { resulting in less effective water flux improvement }\end{array}$ \\
\hline Temperature & $\begin{array}{l}\text { Higher temperature would not only afford higher initial fluxes and higher } \\
\text { water recoveries but also induce more adverse effects on membrane } \\
\text { scaling and cleaning }\end{array}$ \\
\hline $\begin{array}{l}\text { Other } \\
\text { characteristics }\end{array}$ & $\begin{array}{l}\text { Influence the FO process performance. For example, a new class of DS } \\
\text { influen } \\
\text { can display unique properties. Such properties can be particle sizes or } \\
\text { particle agglomeration due to special magnetic properties when using } \\
\text { magnetic nanoparticles (MNPs). Some DS can also act as precursor to } \\
\text { scaling and membrane fouling during reverse diffusion when DS } \\
\text { containing SO }{ }_{4}^{2+} \text { and Mg }{ }^{2+} \text { are used, respectively }\end{array}$ \\
\hline
\end{tabular}




\section{References}

[1] T.M.M. N. Ghaffour, G. L. Amy, Technical review and evaluation of the economics of water desalination: Current and future challenges for better water supply sustainability, Desalination 309 (2013) 197-207.

[2] M. Elimelech, W.A. Phillip, The future of seawater desalination: Energy, technology, and the environment, in: Science, 2011, pp. 712-717.

[3] b. R. Valladares Linares a, Z. Li a, *, S. Sarp c, Sz.S. Bucs a,b, G. Amy a,, J.S. Vrouwenvelder, Forward osmosis niches in seawater desalination

and wastewater reuse, water $r$ e search 66 (2014) 122 2-139.

[4] L.G.-R. B. Peñate, Current trends and future prospects in the design of seawater reverse osmosis desalination technology, Desalination 284 (2012) 1-8.

[5] D.J.J. W. A. Suwaileh, S. Sarp, N. Hilal, Advances in forward osmosis membranes: Altering the sublayer structure via recent fabrication and chemical modification approaches, Desalination 436 (2018) 176-201.

[6] K.Y. Wang, R.C. Ong, T.S. Chung, Double-skinned forward osmosis membranes for reducing internal concentration polarization within the porous sublayer, Industrial and Engineering Chemistry Research, 49 (2010) 4824-4831.

[7] J.X. Changsheng Zhao, Fen Ran, Shudong Sun, Modification of polyethersulfone membranes - A review

of methods, Progress in Materials Science 58 (2013) 76-150.

[8] C.Q. J. Wei, Ch. Y. Tang, R. Wang, A. G. Fanea, Synthesis and characterization of flat-sheet thin film composite forward osmosis membranes, Journal of Membrane Science, 372 (2011) 292-302. [9] P.L. Sh. Zhang, Y. Chen, J. Jin, L. Hu, X. Jian, Preparation of thermally stable composite forward osmosis hollow fiber membranes based on copoly(phthalazinone biphenyl ether sulfone) substrates

Chemical Engineering Science, 166 (2017) 91-100.

[10] C.Y. Tang, Q. She, W.C.L. Lay, R. Wang, A.G. Fane, Coupled effects of internal concentration polarization and fouling on flux behavior of forward osmosis membranes during humic acid filtration, Journal of Membrane Science, 354 (2010) 123-133.

[11] M. Qasim, N.A. Darwish, S. Sarp, N. Hilal, Water desalination by forward (direct) osmosis phenomenon: A comprehensive review, Desalination, 374 (2015) 47-69.

[12] R. Kumar, S. Al-Haddad, M. Al-Rughaib, M. Salman, Evaluation of hydrolyzed poly(isobutylenealt-maleic anhydride) as a polyelectrolyte draw solution for forward osmosis desalination, Desalination, 394 (2016) 148-154.

[13] O.N. I. Ibrar, A. Sharif, A. Malekizadeh, A. Alhawari, A. A. Alanezi, A. Altaee, A review of fouling mechanisms, control strategies and real-time fouling monitoring techniques in forward osmosis, Water, 11 (2019) 1-38.

[14] T.C. Ch. F. Wan, Techno-economic evaluation of various RO+PRO and RO+FO integrated processes, Applied Energy 212 (2018) 1038-1050.

[15] A. Altaee, A. Braytee, G.J. Millar, O. Naji, Energy efficiency of hollow fibre membrane module in the forward osmosis seawater desalination process, Journal of Membrane Science, 587 (2019) 117165.

[16] A.A. Aziz, K.C. Wong, P.S. Goh, A.F. Ismail, I.W. Azelee, Tailoring the surface properties of carbon nitride incorporated thin film nanocomposite membrane for forward osmosis desalination, Journal of Water Process Engineering, 33 (2020) 101005.

[17] W. Xu, Q. Chen, Q. Ge, Recent advances in forward osmosis (FO) membrane: Chemical modifications on membranes for FO processes, in: Desalination, Elsevier B.V., 2017, pp. 101-116.

[18] Y.-N. Wang, K. Goh, X. Li, L. Setiawan, R. Wang, Membranes and processes for forward osmosisbased desalination: Recent advances and future prospects, Desalination, 434 (2018) 81-99. 
[19] A.F.I. P. S. Goh, B. Ch. Ng, M. S. Abdullah, Recent progresses of forward osmosis membranes formulation and design for wastewater treatment, Water, 11 (2019) 1-37.

[20] W.L. Ang, A.W. Mohammad, D. Johnson, N. Hilal, Unlocking the application potential of forward osmosis through integrated/hybrid process, Science of The Total Environment, (2019) 136047.

[21] Y.C. Kim, S.-J. Park, Experimental study of a 4040 spiral-wound forward-osmosis membrane module, Environmental science \& technology, 45 (2011) 7737-7745.

[22] P.L. J. Xu, M. Jiao, B. Shan, C. Gao,, Effect of Molecular Configuration of Additives on the Membrane Structure and Water Transport Performance for Forward Osmosis, ACS Sustainable Chemistry and Engineering, 4 (2016) 4433-4441.

[23] H.L. G. M. Geise, D. J. Miller, B. D. Freeman, J. E. McGrath, D. R. Paul, , Water purification by membranes: The role of polymer science, Journal of Polymer Science, Part B: Polymer Physics, 48 (2010) 1685-1718.

[24] A.T. N. Y. Yip, W. A. Phillip, J. D. Schiffman, E. Menachem, High performance thin-film composite forward osmosis membrane, Environmental Science and Technology, 44 (2010) 3812-3818.

[25] Z.L. X. Song, D. D. Sun, Nano gives the answer: breaking the bottleneck of internal concentration polarization with a nanofiber composite forward osmosis membrane for a high water production rate, Advanced materials, 23 (2011) 3256-3260.

[26] D.J. W. Suwaileh, S. Khodabakhshi, N. Hilal, Development of forward osmosis membranes modified by cross-linked layer by layer assembly for brackish water desalination, Journal of Membrane Science 583 (2019) 267-277.

[27] S.S. Ray, S.-S. Chen, D. Sangeetha, H.-M. Chang, C.N.D. Thanh, Q.H. Le, H.-M. Ku, Developments in forward osmosis and membrane distillation for desalination of waters, Environmental chemistry letters, 16 (2018) 1247-1265.

[28] A. Basile, A. Cassano, N.K. Rastogi, Advances in Membrane Technologies for Water Treatment : Materials, Processes and Applications, Elsevier Science \& Technology, Cambridge, UNITED KINGDOM, 2015.

[29] T.f.f.b.w.p. N. Lubic, Environmental Science \& Te chnology, 2007. Available at: https://pubs.acs.org/doi/pdf/10.1021/es0725706.

[30] K.Y.W. Q. Yang, and T.-S. Chung, Dual-layer hollow fibers with enhanced flux as novel forward osmosis membranes for water production, Environmental science \& technology,, 43 (2009) 28002805.

[31] E. Cornelissen, D. Harmsen, K. Dekorte, C. Ruiken, J. Qin, H. Oo, L. Wessels, Membrane fouling and process performance of forward osmosis membranes on activated sludge, Journal of Membrane Science, 319 (2008) 158-168.

[32] R.W. W. Fang, Sh. Chou, L. Setiawan, A. G. Fane, Composite forward osmosis hollow fiber membranes: Integration of RO-and NF-like selective layers to enhance membrane properties of antiscaling and anti-internal concentration polarization, Journal of Membrane Science, 394 (2012) 140150.

[33] H.W. H. Liu, X. Zhang, , Facile fabrication of freestanding ultrathin reduced graphene oxide membranes for water purification, Advanced materials, 27 (2015) 249-254.

[34] M.M. Pendergast, M.S. Nowosielski-Slepowron, J. Tracy, Going big with forward osmosis, Desalination and Water Treatment, 57 (2016) 26529-26538.

[35] J. Kim, G. Blandin, S. Phuntsho, A. Verliefde, P. Le-Clech, H. Shon, Practical considerations for operability of an 8 "spiral wound forward osmosis module: Hydrodynamics, fouling behaviour and cleaning strategy, Desalination, 404 (2017) 249-258.

[36] ForwardOsmosisTech, Spiral wound forward osmosis membrane modules, in, ForwardOsmosisTech, 2014.

[37] Toyobo, TOYOBO Membrane Business \& Technology, (2017).

[38] G. Blandin, A.R. Verliefde, J. Comas, I. Rodriguez-Roda, P. Le-Clech, Efficiently combining water reuse and desalination through forward osmosis-reverse osmosis (FO-RO) hybrids: a critical review, Membranes, 6 (2016) 37. 
[39] Porifera, PFO-9S MODULE THE IDEAL DESIGN FOR FORWARD OSMOSIS, in, 2016.

[40] C. Tang, Y. Zhao, R. Wang, C. Hélix-Nielsen, A. Fane, Desalination by biomimetic aquaporin membranes: Review of status and prospects, Desalination, 308 (2013) 34-40.

[41] L. Xia, M.F. Andersen, C. Hélix-Nielsen, J.R. McCutcheon, Novel commercial aquaporin flat-sheet membrane for forward osmosis, Industrial \& Engineering Chemistry Research, 56 (2017) 1191911925.

[42] Aquaporin, Aquaporin Inside ${ }^{\circledR}$ Membranes Hollow fiber forward osmosis module, in, 2019.

[43] X. Fan, Y. Liu, X. Quan, S. Chen, Highly permeable thin-film composite forward osmosis membrane based on carbon nanotube hollow fiber scaffold with electrically enhanced fouling resistance, Environmental science \& technology, 52 (2018) 1444-1452.

[44] S.Q. J. Lee, X. Liu, Y. Li, F. Huo, Ch. Y. Tang, , Synthesis and characterization of silica gelpolyacrylonitrile mixed matrix forward osmosis membranes based on layer-by-layer assembly, Separation and Purification Technology 124 (2014) 207-216.

[45] J.R.M. N. Bui, Nanoparticle-embedded nanofibers in highly permselective thin-film nanocomposite membranes for forward osmosis, Journal of Membrane Science 518 (2016) 338-346.

[46] M.S. H. G. Choi, S. H. Yoon, E. Celik, S. Kang, H. Park, Ch. H. Park, H. Choi,, Alginate fouling reduction of functionalized carbon nanotube blended cellulose acetate membrane in forward osmosis, Chemosphere, 136 (2015) 204-210.

[47] W.J.L. D. Emadzadeh, T. Matsuura, N. Hilal, A. F. Ismail, The potential of thin film nanocomposite membrane in reducing organic fouling in forward osmosis process, Desalination 348 (2014) 82-88.

[48] A.E.M. H. M. Hegab, Th. G. Barclay, A. Michelmore, L. Zou, Ch. P. Saint, M. Ginic-Markovic,, Finetuning the surface of forward osmosis membranes via grafting graphene oxide: Performance patterns and biofouling propensity, , ACS Appl. Mater. Interfaces 7(2015) 18004-18016.

[49] W.J.L. D. Emadzadeh, M. Rahbari-Sisakht,T. Matsuura, A. F. Ismail,, A novel thin film composite forward osmosis membrane prepared from PSf-TiO2 nanocomposite substrate for water desalination, Chemical Engineering Journal, 237 (2014) 70-80.

[50] D.S.D. J . Wang, A. K. Mishra, M. Th. M. Pendergast, M. C. Y. Wong, B. B. Mamba, V. Freger, A. R. D. Verliefde, E. M. V. Hoek,, A critical review of transport through osmotic membranes, Journal of Membrane Science 454 (2014) 516-537.

[51] M.J. M. Amini, A. Rahimpour, Synthesis of novel thin film nanocomposite (TFN) forward osmosis membranes using functionalized multi-walled carbon nanotubes, Journal of Membrane Science 435 (2013) 233-241.

[52] L.W. X. Song, Ch. Y. Tang, Z. Wang, C. Gao, , Fabrication of carbon nanotubes incorporated double-skinned thin film nanocomposite membranes for enhanced separation performance and antifouling capability in forward osmosis process, , Desalination 369 (2015) 1-9.

[53] S.R.C. X. Lu, D. L. Shaffer, J. Ma, M. Elimelech,, In situ surface chemical modification of thin-film composite forward osmosis membranes for enhanced organic fouling resistance, Environmental Science and Technology, 47 (2013) 12219-12228.

[54] J.L. C. Liu, J. Ma, M. Elimelech, Antifouling thin-film composite membranes by controlled architecture of zwitterionic polymer brush layer, Environ. Sci. Technol. , 51 (2017) 2161-2169.

[55] Y.L. W. Ding, M. Bao, J. Zhang, C. Zhang, J. Lub, Highly permeable and stable forward osmosis (FO) membrane based on the incorporation of $\mathrm{Al} 2 \mathrm{O} 3$ nanoparticles into both substrate and polyamide active layer, RSC Adv., 7 (2017) 40311-40320.

[56] J.Z. P. H. H. Duong, T. Sh. Chung,, Highly crosslinked layer-by-layer polyelectrolyte FO membranes: Understanding effects of salt concentration and deposition time on FO performance, Journal of Membrane Science, 427 (2013) 411-421.

[57] S.H.W. G. R. Xu, H. L. Zhao, Sh. B. Wu, J. M. Xu, L. Li, X. Y. Liu, Layer-by-layer (LBL) assembly technology as promising strategy for tailoring pressure-driven desalination membranes, in: Journal of Membrane Science, Elsevier, 2015, pp. 428-443.

[58] A.A.M. P. Pardeshi, Synthesis, characterization and application of novel high flux FO membrane by layer-by-layer self-assembled polyelectrolyte, Journal of Membrane Science 453 (2014) 202-211. 
[59] W.A.S. D. J. Johnson, A. Mohammed, N. Hilal,, Osmotic's potential: An overview of draw solutes for forward osmosis, Desalination, 434 (2018) 100-120.

[60] D.J. W. Suwaileh, N. Hilal,, Brackish water desalination for agriculture: Assessing the performance of inorganic fertilizer draw solutions, Desalination, 456 (2019) 53-63.

[61] X.Z. D. Li, J. Yao, G. P. Simon, H. Wang, , Stimuli-responsive polymer hydrogels as a new class of draw agent for forward osmosis desalination, Chem. Commun, 47 (2011) 1710-1712.

[62] D.J. Johnson, W.A. Suwaileh, A.W. Mohammed, N. Hilal, Osmotic's potential: An overview of draw solutes for forward osmosis, Desalination, 434 (2018) 100-120.

[63] J. Yaeli, Method and apparatus for processing liquid solutions of suspensions particularly useful in the desalination of saline water, in, Google Patents, 1992.

[64] Y. Cai, X.M. Hu, A critical review on draw solutes development for forward osmosis, Desalination, 391 (2016) 16-29.

[65] R.L.M. J. R. Mccutcheon, M. Elimelech, , Desalination by ammonia-carbon dioxide forward osmosis: Influence of draw and feed solution concentrations on process performance, Journal of Membrane Science, 278 (2006) 114-123.

[66] C.H.L. X. Li, R. Wang, W. Widjajanti, J. Torres,, Fabrication of a robust high-performance FO membrane by optimizing substrate structure and incorporating aquaporin into selective layer, Journal of Membrane Science 525 (2017) 257-268.

[67] S. Adham, J. Oppenheimer, L. Liu, M. Kumar, Dewatering reverse osmosis concentrate from water reuse applications using forward osmosis, Water Use Foundation Research Report, (2007).

[68] S.C. D. Zhao, P. Wang, Q. Zhao, X. Lu, A dendrimer-based forward osmosis draw solute for seawater desalination, Industrial and Engineering Chemistry Research, 53 (2014) 16170-16175.

[69] S.Y. Y. Na, S. Lee, Evaluation of citrate-coated magnetic nanoparticles as draw solute for forward osmosis, Desalination, 347 (2014) 34-42.

[70] D. Li, X. Zhang, J. Yao, G.P. Simon, H. Wang, Stimuli-responsive polymer hydrogels as a new class of draw agent for forward osmosis desalination, Chemical Communications, 47 (2011) 1710-1712.

[71] R.W. Y. Cai, W. B. Krantz, A. G. Fane, X. Hu, Exploration of using thermally responsive polyionic liquid hydrogels as draw agents in forward osmosis, RSC Advances

5(2015) 97143-97150.

[72] S. Phuntsho, H.K. Shon, S. Hong, S. Lee, S. Vigneswaran, A novel low energy fertilizer driven forward osmosis desalination for direct fertigation: Evaluating the performance of fertilizer draw solutions, Journal of Membrane Science, 375 (2011) 172-181.

[73] M.L. Stone, C. Rae, F.F. Stewart, A.D. Wilson, Switchable polarity solvents as draw solutes for forward osmosis, Desalination, 312 (2013) 124-129.

[74] C.X. Guo, D. Zhao, Q. Zhao, P. Wang, X. Lu, Na+-functionalized carbon quantum dots: a new draw solute in forward osmosis for seawater desalination, Chemical Communications, 50 (2014) 7318-7321.

[75] Q. Long, Y. Jia, J. Li, J. Yang, F. Liu, J. Zheng, B. Yu, Recent Advance on Draw Solutes Development in Forward Osmosis, Processes, 6 (2018) 165.

[76] S.Y. Y. Hartanto, B. Jin, Sh. Sheng, Functionalized thermo-responsive microgels for high performance forward osmosis desalination, Water Research, 70 (2015) 385-393.

[77] W.A.P. J. Sh. Yong, M. Elimelech, Coupled reverse draw solute permeation and water flux in forward osmosis with neutral draw solutes, Journal of Membrane Science, 392-393 (2012) 9- 17.

[78] P.J.B. S. B. S Ghayeni, R. P. Schneider, A. G. Fane, Water reclamation from municipal wastewater using combined microfiltration-reverse osmosis (ME-RO): Preliminary performance data and microbiological aspects of system operation, Desalination, 116 (1998) 65-80.

[79] L.F. R. Schneider, P. Binder, J. Ramos, Analysis of foulant layer in all elements of an RO train, Journal of Membrane Science, 261 (2005) 152-162.

[80] C.H. M. Qiu, Novel zwitterion-silver nanocomposite modified thin-film composite forward osmosis membrane with simultaneous improved water flux and 
biofouling resistance property, Applied Surface Science, 455 (2018) 492-501.

[81] R.R.G. M. J. Park, A. Abdel-Wahab, S. Phuntsho, H. K. Shon, Hydrophilic polyvinyl alcohol coating on hydrophobic electrospun nanofiber membrane for high performance thin film composite forward osmosis membrane, Desalination, 426 (2018) 50-59.

[82] Q.C. F. Li, Q. Tian, B. Yang, Q. Chen, Biofouling behavior and performance of forward osmosis membranes with bioinspired surface modification in osmotic membrane bioreactor, Bioresource Technology, 211 (2016) 751-758.

[83] Y.W. Sh. Zou, F. Wicaksana, Th. Aung, Ph. Ch. Y. Wong, A. G. Fane, Ch. Y. Tang, Direct microscopic observation of forward osmosis membrane fouling by microalgae: Critical flux and the role of operational conditions, Journal of Membrane Science, 436 (2013) 174-185.

[84] N. Pathak, L. Fortunato, S. Li, L. Chekli, S. Phuntsho, N. Ghaffour, T. Leiknes, H.K. Shon, Evaluating the effect of different draw solutes in a baffled osmotic membrane bioreactormicrofiltration using optical coherence tomography with real wastewater, Bioresource technology, 263 (2018) 306-316.

[85] A. Haupt, A. Lerch, Forward osmosis application in manufacturing industries: a short review, Membranes, 8 (2018) 47.

[86] K.Y. Wang, R.C. Ong, T.-S. Chung, Double-skinned forward osmosis membranes for reducing internal concentration polarization within the porous sublayer, Industrial \& Engineering Chemistry Research, 49 (2010) 4824-4831.

[87] T. Cath, A. Childress, M. Elimelech, Forward osmosis: Principles, applications, and recent developments, Journal of Membrane Science, 281 (2006) 70-87.

[88] P.G. Nicoll, Forward osmosis-A brief introduction, in: Proceedings of the international desalination association world congress on desalination and water reuse, Tianjin, China, 2013, pp. 20-25.

[89] R.L.M. J. R. Mccutcheon, E. Menachem, A novel ammonia-carbon dioxide forward (direct) osmosis desalination process, in: Desalination, 2005, pp. 1-11.

[90] V. Sant'Anna, L.D.F. Marczak, I.C. Tessaro, Membrane concentration of liquid foods by forward osmosis: Process and quality view, Journal of Food Engineering, 111 (2012) 483-489.

[91] A.V.T. K. B. Petrotos, E. Poirazis, D. Papadopoulos, H. Petropakis, P. Gkoutsidis, A description of a flat geometry direct osmotic concentrator to concentrate tomato juice at ambient temperature and low pressure. Journal of food engineering, , Journal of Food Engineering, 97 (2010) 235-242.

[92] V.D.A. M. P. Marques, I. M. Coelhoso, , Concentration of tea extracts by osmotic evaporation: optimisation of process parameters and effect on antioxidant activity,, Membranes,, 7 (2017) 1.

[93] A. Martin, Forward Osmosis in food and beverage processing, Food New Zealand, 19 (2019) 49.

[94] A. Achilli, T.Y. Cath, E.A. Marchand, A.E. Childress, The forward osmosis membrane bioreactor: A low fouling alternative to MBR processes, Desalination, 239 (2009) 10-21.

[95] N. Pathak, L. Chekli, J. Wang, Y. Kim, S. Phuntsho, S. Li, N. Ghaffour, T. Leiknes, H. Shon, Performance of a novel baffled osmotic membrane bioreactor-microfiltration hybrid system under continuous operation for simultaneous nutrient removal and mitigation of brine discharge, Bioresource technology, 240 (2017) 50-58.

[96] N. Pathak, S. Li, Y. Kim, L. Chekli, S. Phuntsho, A. Jang, N. Ghaffour, T. Leiknes, H.K. Shon, Assessing the removal of organic micropollutants by a novel baffled osmotic membrane bioreactormicrofiltration hybrid system, Bioresource technology, 262 (2018) 98-106.

[97] N.A. Thompson, P.G. Nicoll, Forward osmosis desalination: a commercial reality, in: IDA World Congress-Perth Convention and Exhibition Centre (PCEC), Perth, Western Australia September, 2011, pp. 4-9.

[98] D, WR, Small FO desalination plant commissioned in Oman, in, The International Desalination \& Water Reuse Quarterly industry

website, 2012. 
[99] T.C. Zhang, Y. Yuan, R.Y. Surampalli, Forward Osmosis Processes for Desalination: Evolution, Case Studies, and Future Directions, in: Forward Osmosis: Fundamentals and Applications, 2015, pp. 303-338.

[100] TreviSystems, Energy Efficient DESALINATION, in, 2020.

[101] Forward OsmosisTech, Integrating forward osmosis in thermal desalination processes, in, Forward Osmosis Tech, , (2016).

[102] M. Yaqub, W. Lee, Zero-liquid discharge (ZLD) technology for resource recovery from wastewater: A review, Sci. Total Environ, 681 (2019) 551-563.

[103] OasysWater, Power Plant Wastewater: Changxing, in, Oyasys Water, 2017.

[104] R. Wünsch, et al., , Water recovery by forward osmosis from challenging industrial effluents towards zero liquid discharge: Selection of a suitable draw solution, , Proceedings of the 12.

Aachener Tagung Wassertechnologie, Aachen, Germany ,, (2017) 24-25.

[105] I.P. N. Singh, C. Helix-Nielsen, S. Basu, M. Balakrishnan, , Concentrating molasses distillery wastewater using biomimetic forward osmosis (FO) membranes, Water Research, 130 (2018) 271280.

[106] J.Y. Law, A.W. Mohammad, Osmotic concentration of succinic acid by forward osmosis: Influence of feed solution $\mathrm{pH}$ and evaluation of seawater as draw solution, Chinese Journal of Chemical Engineering, 26 (2018) 976-983.

[107] M.J. Luján-Facundo, J.L. Soler-Cabezas, J.A. Mendoza-Roca, M.C. Vincent-Vela, A. Bes-Piá, S. Doñate-Hernández, A study of the osmotic membrane bioreactor process using a sodium chloride solution and an industrial effluent as draw solutions, Chemical Engineering Journal, 322 (2017) 603610.

[108] J.L. Soler-Cabezas, J.A. Mendoza-Roca, M.C. Vincent-Vela, M.J. Luján-Facundo, L. PastorAlcañiz, Simultaneous concentration of nutrients from anaerobically digested sludge centrate and pre-treatment of industrial effluents by forward osmosis, Separation and Purification Technology, 193 (2018) 289-296.

[109] G. Gwak, D.I. Kim, S. Hong, New industrial application of forward osmosis (FO): Precious metal recovery from printed circuit board (PCB) plant wastewater, Journal of Membrane Science, 552 (2018) 234-242.

[110] forwardOsmosisTech, Update: Forward Water Technologies' industrial scale pilot plant is demonstrating low energy ZLD, in, 2020.

[111] M.W. D. L. Oatley-Radcliffea, Th. J. Ainscough, P. M. Williamsa, A. Mohammad, N. Hilal, Nanofiltration membranes and processes: A review of research trends over the past decade, Journal of Water Process Engineering 19 (2017) 164-171.

[112] F.I.H. A. J. Ansaria, W. E. Priceb, J. E. Drewesc, L. D. Nghiema, Forward osmosis as a platform for resource recovery from municipal wastewater - A critical assessment of the literature, Journal of Membrane Science 529 (2017) 195-206.

[113] G.J. S. Im, S. Jeong, J. Cho, A. Jang, Fouling and transport of organic matter in cellulose triacetate forwardosmosis membrane for wastewater reuse and seawater desalination, Chemical Engineering Journal 384 (2020) 123341.

[114] Z.F. Y. Gao, P. Liang, X. Huang, Direct concentration of municipal sewage by forward osmosis and membrane fouling behavior, Bioresource Technology, 247 (2018) 730-735.

[115] Y.G. L. Chen, Ch. Cao, J. Zhang, J. Ng, Ch. Tang, , Performance of a submerged anaerobic membrane bioreactor with forward osmosis membrane for low-strength wastewater treatment, Water Research, 50 (2014) 114-123.

[116] D. Roy, M. Rahni, P. Pierre, V. Yargeau, Forward osmosis for the concentration and reuse of process saline wastewater, Chemical Engineering Journal, 287 (2016) 277-284.

[117] D. Roy, A.K. Mostafazadeh, P. Drogui, R.D. Tyagi, Emerging Organic Micro-Pollutants, Elsevier, Cambridge, MA 02139, United States, 2020.

[118] R. Valladares Linares, Z. Li, S. Sarp, S.S. Bucs, G. Amy, J.S. Vrouwenvelder, Forward osmosis niches in seawater desalination and wastewater reuse, Water research, 66 (2014) 122-139. 
[119] L. Chekli, S. Phuntsho, J.E. Kim, J. Kim, J.Y. Choi, J.-S. Choi, S. Kim, J.H. Kim, S. Hong, J. Sohn, A comprehensive review of hybrid forward osmosis systems: Performance, applications and future prospects, Journal of Membrane Science, 497 (2016) 430-449.

[120] S. Phuntsho, H.K. Shon, S. Hong, S. Lee, S. Vigneswaran, J. Kandasamy, Fertiliser drawn forward osmosis desalination: the concept, performance and limitations for fertigation, Reviews in Environmental Science and Bio/Technology, 11 (2011) 147-168.

[121] S. Phuntsho, H.K. Shon, S. Hong, S. Lee, S. Vigneswaran, A novel low energy fertilizer driven forward osmosis desalination for direct fertigation: Evaluating the performance of fertilizer draw solutions, Journal of Membrane Science, 375 (2011) 172-181.

[122] S. Phuntsho, S. Hong, M. Elimelech, H.K. Shon, Forward osmosis desalination of brackish groundwater: Meeting water quality requirements for fertigation by integrating nanofiltration, Journal of Membrane Science, 436 (2013) 1-15.

[123] S. Sahebi, S. Phuntsho, J.E. Kim, S. Hong, H.K. Shon, Pressure assisted fertiliser drawn osmosis process to enhance final dilution of the fertiliser draw solution beyond osmotic equilibrium, Journal of Membrane Science, 481 (2015) 63-72.

[124] A. Altaee, N. Hilal, High recovery rate NF-FO-RO hybrid system for inland brackish water treatment, Desalination, 363 (2015) 19-25.

[125] Z.H. S. Zou, Enhancing wastewater reuse by forward osmosis with self-diluted commercial fertilizers as draw solutes, Water Res., 99 (2016) 235-243.

[126] M.B. A. Subramani, J. Oppenheimer, J. G. Jacangelo, Energy minimization strategies and renewable energy utilization for desalination: A review, Water Research, 45 (2011) 1907-1920.

[127] T. Xie, Tunable polymer multi-shape memory effect, Nature, 464 (2010) 267-270.

[128] H.J. A. Lendlein, O. Ju"nger, R. Langer, Light-induced shape-memory polymers, Nature, 434 (2005) 879-882.

[129] R.H. Sh. F. Anis, N. Hilal, Microfiltration membrane processes: A review of research trends over the past decade, Journal of Water Process Engineering, 32 (2019) 100941.

[130] J.R. M. R. Chowdhury, K. Reimund, J. R. McCutcheon,, A hybrid dead-end/cross-flow forward osmosis system for evaluating osmotic flux performance at high recovery of produced water, Desalination, 421 (2017) 127-134.

[131] N.G. G. Amy, Z. Li, L. Francis, R. V. Linares, Th. Missimer, S. Lattemann, Membrane-based seawater desalination: Present and future prospects, Desalination 401 (2017) 16-21.

[132] L. Chekli, S. Phuntsho, H.K. Shon, S. Vigneswaran, J. Kandasamy, A. Chanan, A review of draw solutes in forward osmosis process and their use in modern applications, Desalination and Water Treatment, 43 (2012) 167-184. 


\section{Supplementary Information}

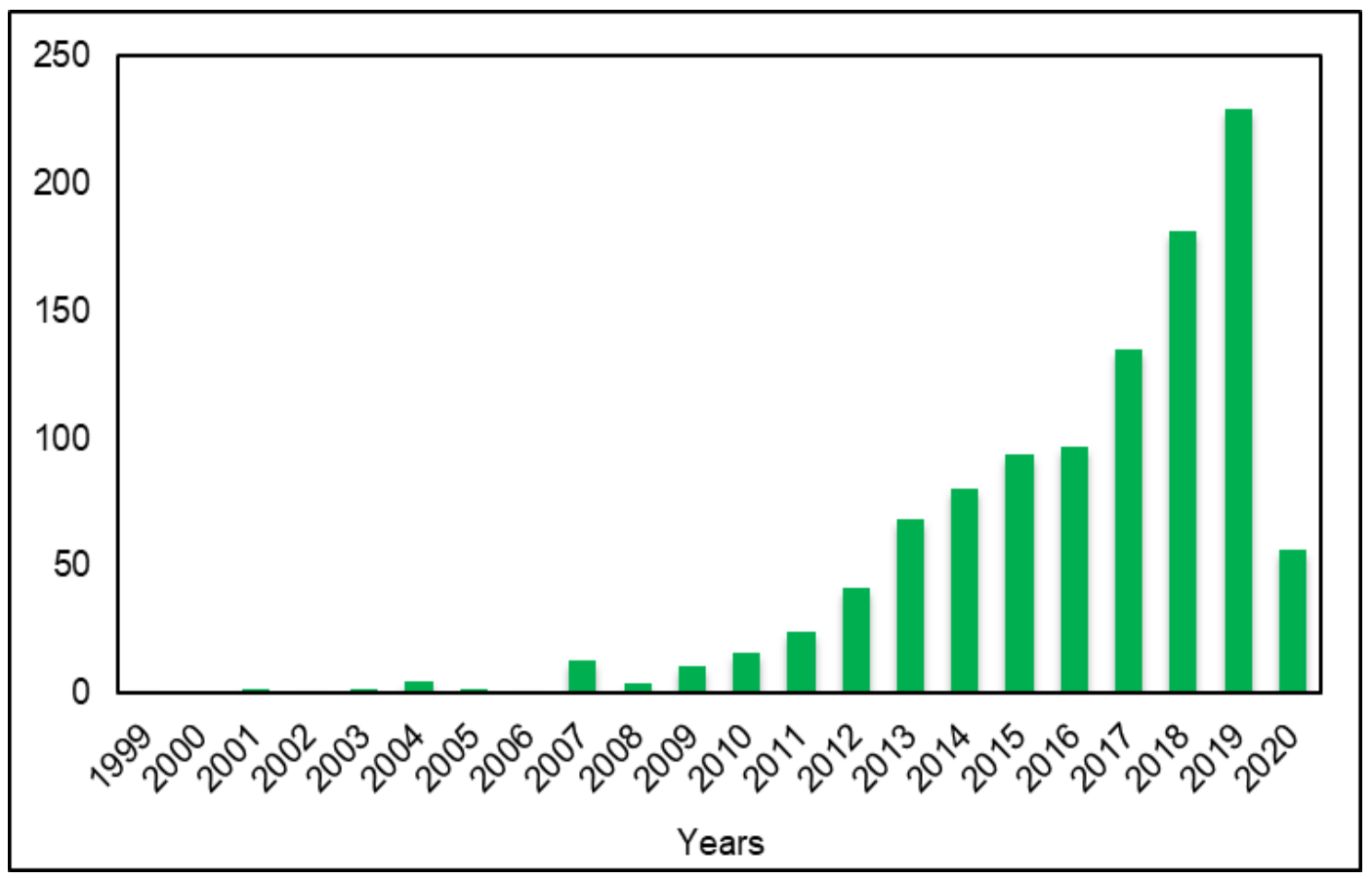

Figure.S1: Research trend of the fabrication and modification of FO membranes including review and technical papers from 1999 to 2020. 


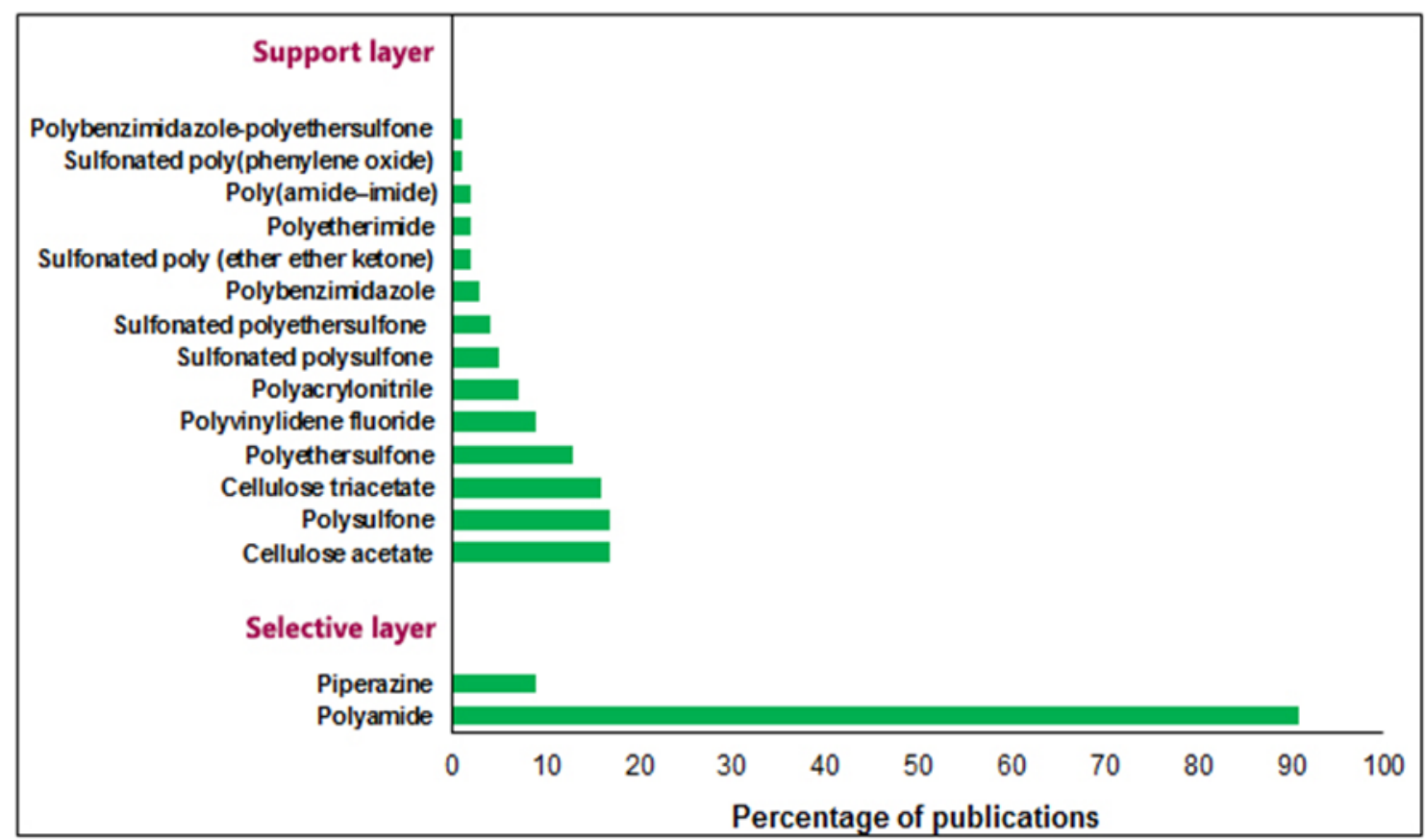

Figure.S2: The percentage of the most popular polymers and materials used for the fabrication and modification of both the support layer and the selective layer of flat sheet and hollow fiber FO membranes.

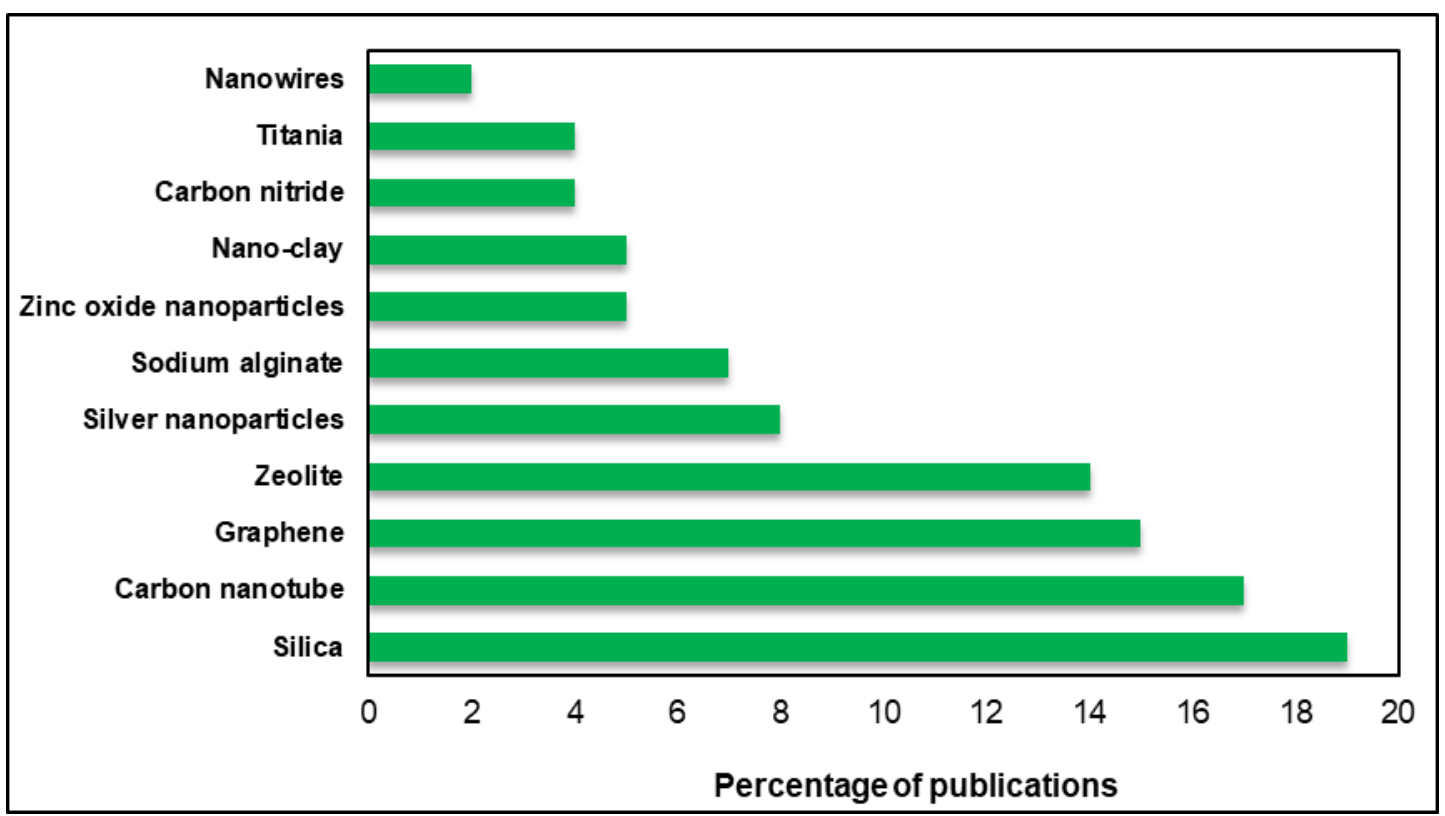

Figure.S3: The percentage of the most widely used Nano-additives in the fabrication and modification of flat sheet and hollow fiber FO membranes. 


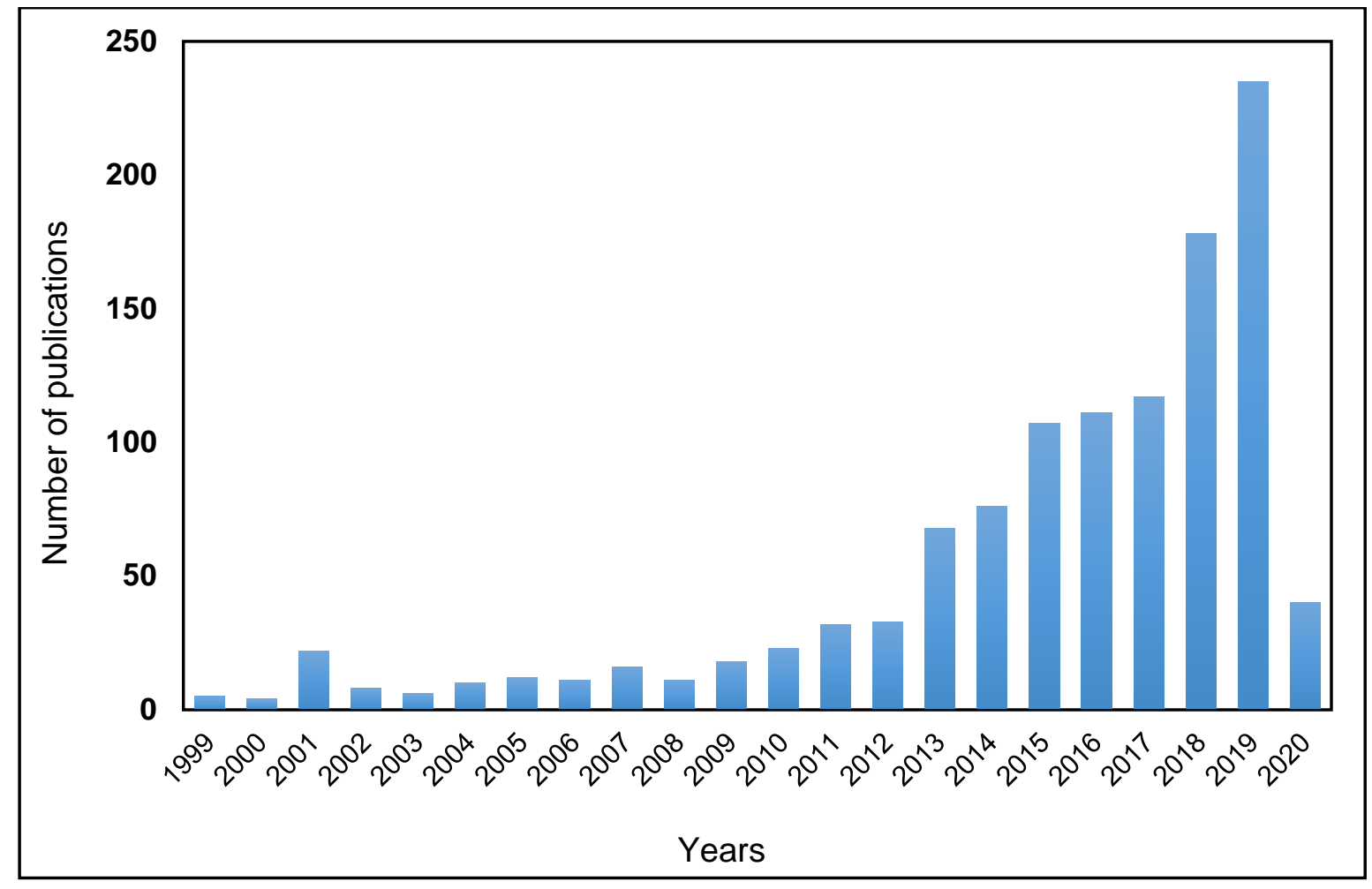

Figure. S4: (a) The research trend on recovery system for the draw solution from 1999 to 2020.

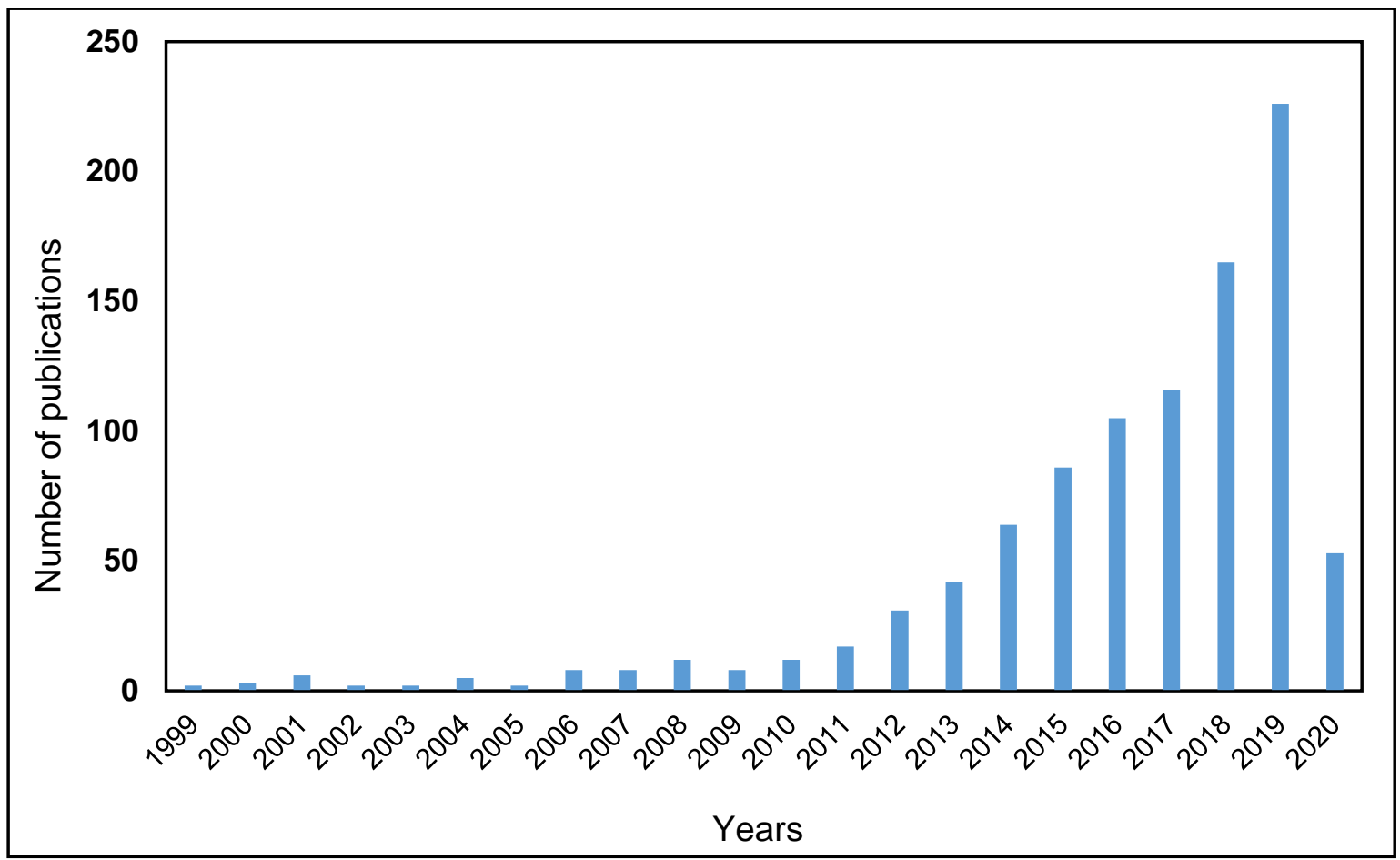

Figure. S4: (b) The research trend on energy consumption of FO process from 1999 to 2020. 


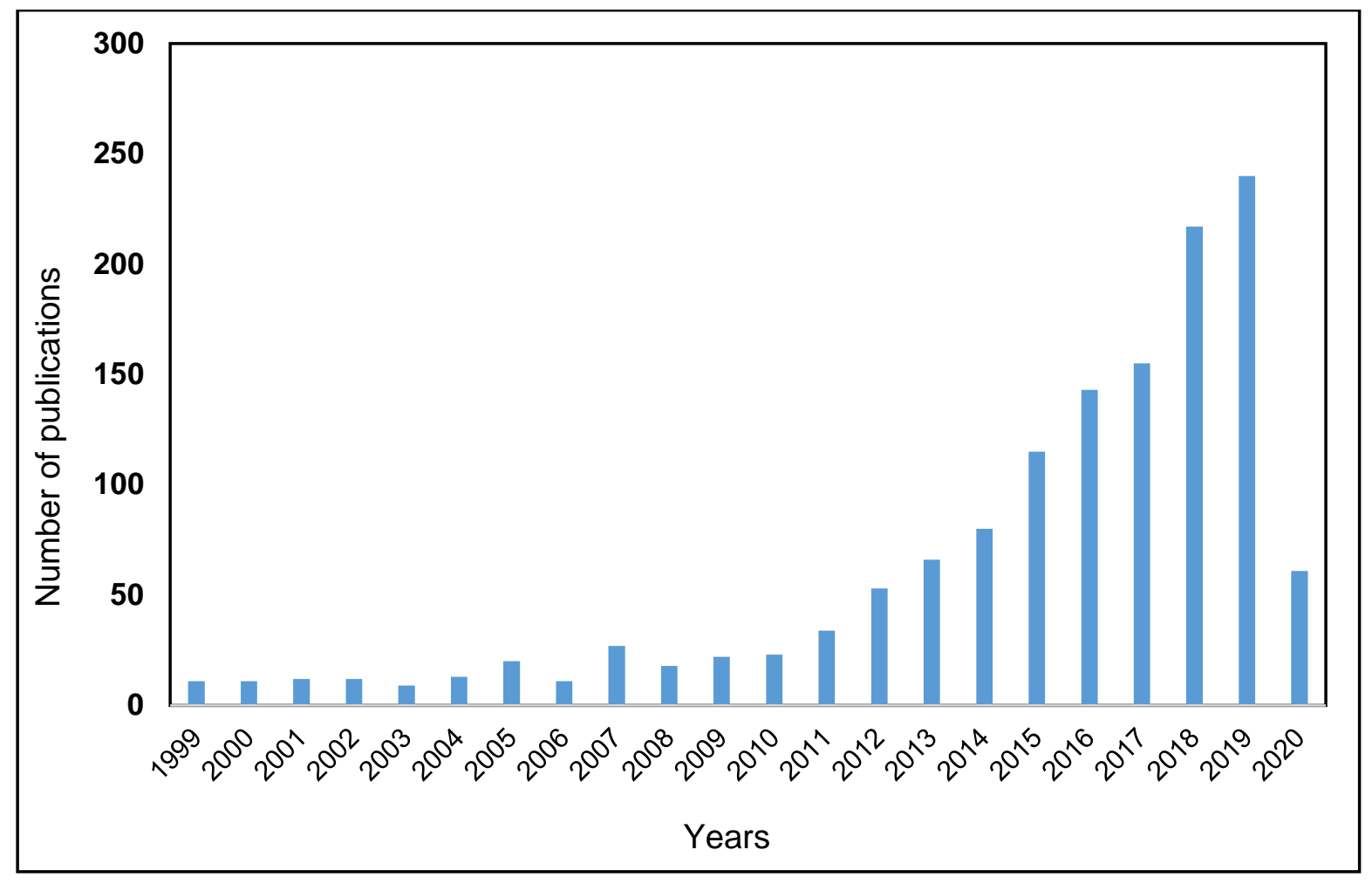

Figure. S4: (c) The research trend on the removal of organic matter in wastewater from 1999 to 2020. 